\title{
Analytical approaches for studying oxygenated lipids in the search of potential biomarkers by LC-MS
}

\author{
Alma Villaseñor ${ }^{\mathrm{a}, \mathrm{b}}$, Joanna Godzien ${ }^{\mathrm{c}}$, Tomás Clive Barker-Tejeda ${ }^{\mathrm{a}, \mathrm{b}}$, \\ Carolina Gonzalez-Riano a , Ángeles López-López a, Danuta Dudzik d, Ana Gradillas a , \\ Coral Barbas ${ }^{\mathrm{a}, *}$ \\ ${ }^{a}$ Centre for Metabolomics and Bioanalysis (CEMBIO), Department of Chemistry and Biochemistry, Facultad de Farmacia, Universidad San Pablo-CEU, CEU \\ Universities, Urbanización Montepríncipe, 28660, Boadilla Del Monte, Madrid, Spain \\ b Departamento de Ciencias Médicas Básicas, Instituto de Medicina Molecular Aplicada (IMMA), Facultad de Medicina, Universidad San Pablo-CEU, CEU \\ Universities, Urbanización Montepríncipe, 28660, Boadilla Del Monte, Madrid, Spain \\ ${ }^{\mathrm{c}}$ Metabolomics Laboratory, Clinical Research Centre, Medical University of Bialystok, 15-089, Bialystok, Poland \\ ${ }^{\mathrm{d}}$ Department of Biopharmaceutics and Pharmacodynamics, Faculty of Pharmacy, Medical University of Gdansk, 80-416, Gdańsk, Poland
}

\section{A R T I C L E I N F O}

\section{Article history:}

Available online 16 June 2021

\section{Keywords:}

Oxidized lipids

Biomarkers

LC-MS analysis

Annotation

Lipidomics

Oxysterols

Oxidized phospholipids

Sphingolipids

Acylcarnitines

Oxidized cholesteryl esters

\begin{abstract}
A B S T R A C T
Great advances in lipidomics during the last years have opened the door to a broader knowledge of oxygenated lipids. These substances are derived either from the inclusion of previously hydroxylated fatty acids in the lipid structure of sphingolipids and acyl-L-carnitines, or by enzymatic and nonenzymatic modifications (oxidized lipids) of glycerophospholipids (including cardiolipins), cholesteryl esters and cholesterol. Despite their significance in the regulation of multiple diseases such as cancer or diabetes, the number of experimentally detected oxygenated lipids remains relatively low. This is in part due to the main challenges in their analysis, which are their low natural concentrations, their wide diversity of physicochemical properties, presence of isomers, and their a priori unknown presence in the biological samples. In particular, analysis of oxidized lipids, especially peroxides, has become a daunting task in liquid chromatography coupled to mass spectrometry (LC-MS) due to their high chemical and thermal instability, and the potential for further propagation of lipid oxidation and eventual degradation. The aim of this review is to highlight the experimental conditions on sample preparation procedures, the LC-MS based analytical approaches for identification and quantification of oxygenated lipids, and their relation as potential biomarkers in diseases based on the most relevant articles published in the last five years. Regarding sample preparation, special attention has been given to antioxidants, internal standards, extraction and concentration methods, and derivatization approaches. Moreover, targeted, semi-targeted and non-targeted strategies have been discussed presenting examples. Finally, considerations on the structural identification, one of the main challenges, are presented.
\end{abstract}

๑) 2021 Elsevier B.V. All rights reserved.

\section{Introduction}

The study of the lipidome has become crucial as lipids have shown multiple biological functions ranging from structural building blocks to regulation of the metabolism [1-3]. The

\footnotetext{
* Corresponding author. Fax: +34913510496.

E-mail addresses: alma.villasenor@ceu.es (A. Villaseñor), joanna.godzien@umb. edu.pl (J. Godzien), tomas.barkertejeda@ceu.es (T.C. Barker-Tejeda), carolina. gonzalezriano@ceu.es (C. Gonzalez-Riano), ang.lopez.ce@ceindo.ceu.es (Á. LópezLópez), danuta.dudzik@gumed.edu.pl (D. Dudzik), gradini@ceu.es (A. Gradillas), cbarbas@ceu.es (C. Barbas).
}

evolution of lipidomics and its importance in biomedical studies for the large-scale determination of individual lipid species has been exponential. The topic has aroused such interest that over the last two years it has been the subject of excellent reviews covering the most recent advances in the most crucial steps in the lipidomic workflow and its applications [4-7]. However, despite the rapid growth of the field in expanding the coverage of the lipidome, there is still no roadmap when it comes to the analysis of oxygenated lipids. Efforts have been initiated [8-10] but the methodologies are still not standardized, and the experimental designs are still not clear, which remains a challenge. 
Oxygenated lipids - lipid metabolites with addition of oxygen into the structure - are derived from the inclusion of previously hydroxylated fatty acids in the lipid structure [11-13] or by enzymatic and non-enzymatic modifications (oxidized lipids) [14-16]. They have attracted the attention of researchers, who have seen that some of these molecules are inherently linked to oxidative stress and have appeared dysregulated in different diseases such as cancer, Alzheimer's disease (AD), diabetes mellitus, metabolic syndrome, atherosclerosis or Niemann-Pick type C disease (NPC), among others, increasing their interest as potential biomarkers (Fig. 1), [17-27]. The huge number of different oxygenated lipids, defined by the degree of oxidative modification, present a high structural diversity with an extensive chemical heterogeneity given by the presence of functional oxygen-containing groups that include: alcohols $(-\mathrm{OH})$, hydroperoxides $(-\mathrm{OOH})$, epoxides $(-\mathrm{O}-)$, aldehydes, ketones $(=\mathrm{O})$, and carboxylic acids $(-\mathrm{COOH})$. Such remarkable chemical complexities, also rich in isomeric species, result in an extensive range of physical properties such as solubility and polarity. Besides their chemical variety, these compounds are in low abundance, there is a lack of knowledge about their diversity in the biological matrices, and they present chemical and thermal instability. These factors impact the measurement of oxygenated lipids and constitute real pitfalls for researchers who must take great care when isolating, analyzing and identifying them from biological samples [9].

High-throughput analytical techniques such as liquid chromatography coupled to mass spectrometry (LC-MS) have provided evidence of their capabilities to study oxygenated lipids in complex biological samples. Suitable analytical methods and conditions are critical for the success of the qualitative and quantitative analyses [5,28].

The aim of this review will be to gather the efforts of current research which has specifically studied oxygenated lipids as potential biomarkers by LC-MS methods used in modern bioanalysis. The focus will be made, from the methodological point of view, on the analytical equipment and strategies that may favor the screening, annotation and quantification processes for the reliable analysis of oxygenated lipids.

Given the number of oxygenated lipid species that have been reported, the potential biomarkers covered in this review have been divided into three main classes according to their progenitor classes and origin, (Fig. 1). Class I encompasses oxygenated lipids containing 2- and 3-hydroxy fatty acids from enzymatic origin hydroxylated sphingolipids (SP $(2 \mathrm{OH})$ ), hydroxylated and dicarboxylic acyl-L-carnitines (CAR (3OH) and CAR (DC), respectively). Class II covers the oxygenated lipids containing polyunsaturated fatty acids peroxidation products - oxidized glycerophospholipids (OxGP), including oxidized cardiolipins (OxCL), and oxidized cholesteryl esters (OxCE). Finally, Class III includes the oxygenated lipids derived from cholesterol peroxidation - oxysterols.

Within the high diversity of oxygenated lipids, oxylipins - which are a large family of lipid mediators formed by the controlled oxygenation of polyunsaturated fatty acids (PUFAs) - represent the most studied group; thus, they have not been included in this work since they have been extensively covered elsewhere [29,30].

The present review will provide comparative information about the most relevant articles published in the last five years which have focused on the analytical methodology. Here, we highlight the experimental conditions on sample preparation procedures (Tables 1.1-1.3), the LC-MS-based analytical approaches for identification and quantification of oxygenated lipids (Tables 2.1-2.3), and their relation as potential biomarkers in diseases (Supporting Tables S1.1-S1.3). We provide examples throughout the text by referencing the tables with their corresponding entry number, which is common to all tables. This review should be read in parallel with the tables.
We have made great efforts to unify all the reported data regarding methodologies, workflows and data presentation, improving the overall understanding of oxygenated lipid analysis. In particular, the nomenclature used follows the latest update of the shorthand notation [68], and is presented in Supporting Tables S2-S6. The result of these efforts, presented in this review, should be particularly useful to researchers that are new to the oxygenated lipidomics field and should help the reader in their experimental design, and thus make the optimization process less time-consuming. Moreover, if the abbreviations proposed in the nomenclature were adopted in future reports, the scientific community would be greatly aided in comparing the results from different assays.

\section{Progenitor classes and origin of oxygenated lipids}

\subsection{Class I. Oxygenated lipids containing 2- and 3-hydroxy fatty} acids. 2-Hydroxysphingolipids and 3-hydroxy and dicarboxylic acyll-carnitines

Sphingolipids (SP) are bioactive compounds which are part of the cellular structure, mainly as components of lipid rafts, and regulators of the cellular functions, such as cell growth and differentiation, proliferation, and apoptosis [69]. Three of the main groups are ceramides (Cer), sphingomyelins (SM) and glycosphingolipids (GSL) - encompassing cerebrosides and gangliosides. Separately, acyl-L-carnitines play an essential role in energy metabolism and are necessary to transport fatty acids across the inner mitochondrial membrane for subsequent $\beta$-oxidation [70]. SP $(2 \mathrm{OH})$ and CAR $(3 \mathrm{OH})$ are the result of the inclusion of 2- and 3hydroxy fatty acids (FA (2OH) and FA (3OH)) in their structures, respectively, by enzymatic mechanisms. FA $(2 \mathrm{OH})$ are produced from free fatty acids by the action of the enzyme fatty acid-2hydroxylase and are subsequently used in the biosynthesis of SP (2OH) [11,71]. These hydroxylations have shown to exert a dramatic impact in their biological function compared to their nonhydroxylated counterparts [71,72]. FA $(3 \mathrm{OH})$ are derived from peroxisomal $\alpha$-oxidation of branched-chain fatty acids, and are later incorporated to L-carnitine to produce CAR (3OH) [13]. Moreover, acyl-L-carnitines can also undergo oxidation producing CAR (DC). These are produced due to an accumulation of acylcoenzyme $A$ in the cytosol caused by an impaired $\beta$-oxidation, which may lead to an increased fatty acid $\omega$-oxidation in the endoplasmic reticulum that occurs mainly in the liver [12,13]. In addition, for SPs, other oxygenated derivatives such as phytoCer or omega-hydroxylated Cer exist, but they have not been included in this review since we did not find any studies detecting them which fulfilled the inclusion criteria [73].

\subsection{Class II. Oxygenated lipid containing polyunsaturated fatty acids peroxidation products. Oxidized glycerophospholipids and oxidized cholesteryl esters}

Glycerophospholipids (GPs) are contained in the cell membrane and have important roles as signaling molecules. Cardiolipins (CLs) are a special class of GPs as they are formed by two phosphoglycerol moieties linked via glycerol, and four fatty acid chains. Furthermore, CLs are almost exclusively located in the mitochondrial inner membrane and are specifically peroxidized under oxidative stress state [56]. Additionally, cholesteryl esters (CEs) are main components of low-density lipoproteins (LDL), residing in the hydrophobic core, and constitute the main transport form of cholesterol from the liver to the periphery $[17,74,75]$.

GPs and CEs are two groups characterized by containing PUFAs in their structure, which are highly prone to oxidation. This process can occur both enzymatically and non-enzymatically via reactive oxygen 
(A) Class I. Oxygenated lipids containing 2- and 3-hydroxy fatty acids.

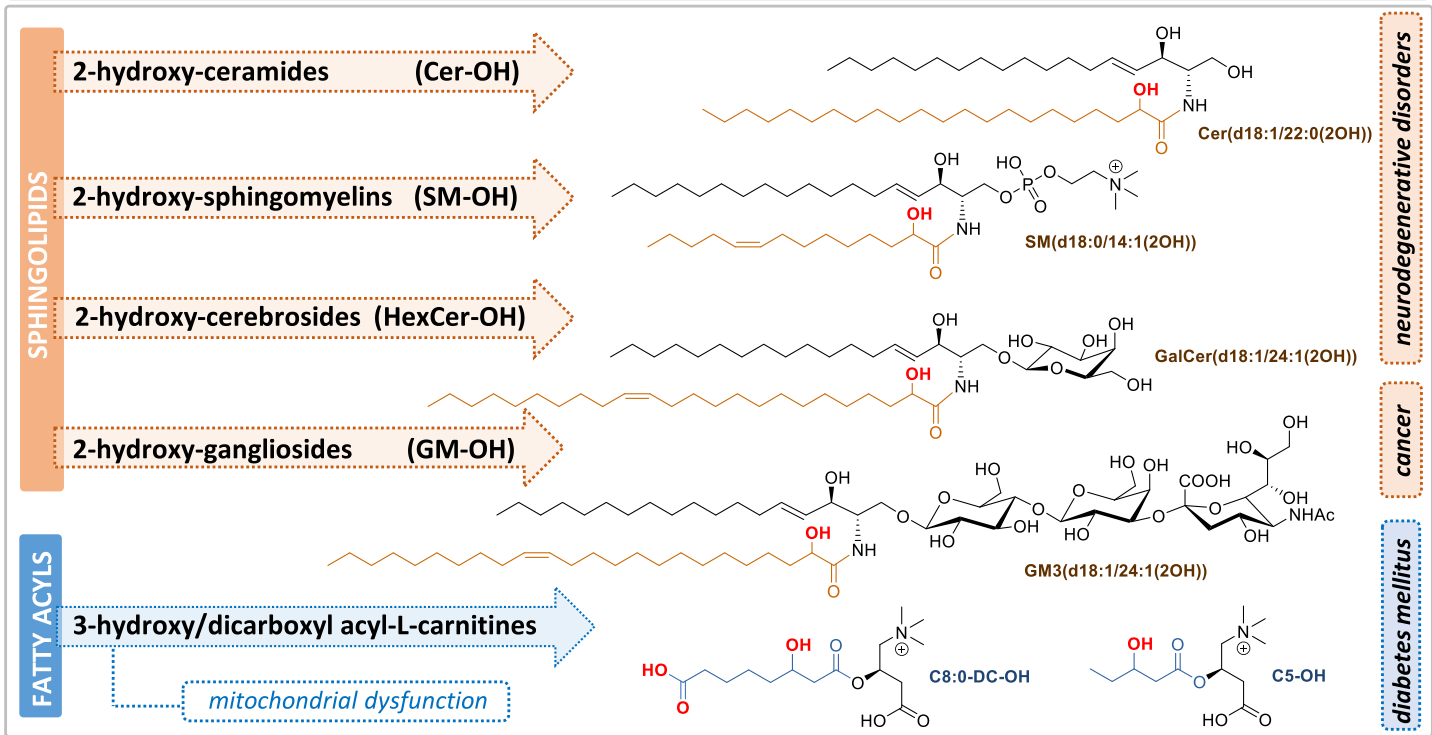

(B) Class II. Oxygenated lipids containing polyunsaturated fatty acids peroxidation products.

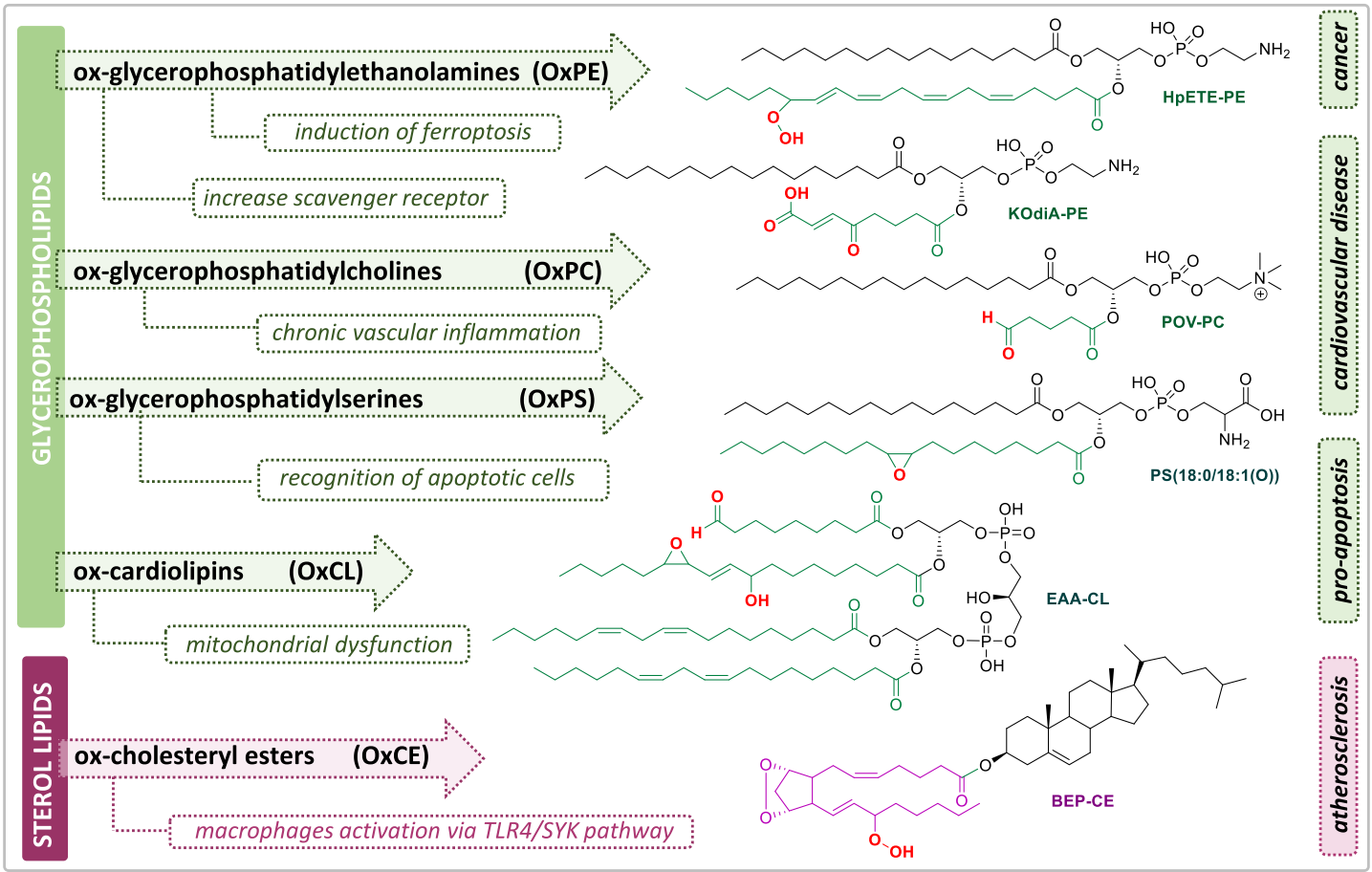

(C) Class III. Oxygenated lipids derived from cholesterol peroxidation.
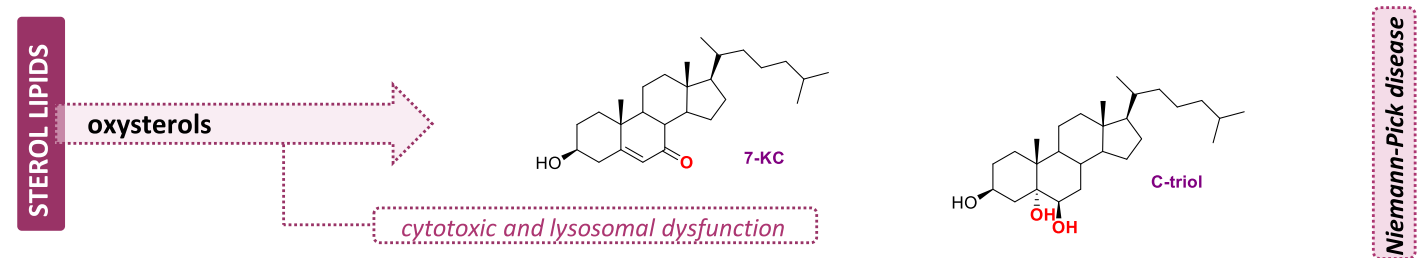

Fig. 1. Oxygenated lipids that have been identified as potential biomarkers, classified according to the origin of their oxygen-containing functional groups. A representative structure is shown for each class of products described in the literature in relation to various diseases. 
Table 1.1

CLASS I - SAMPLE PREPARATION - Oxygenated lipids containing 2- and 3-hydroxy fatty acids.

\begin{tabular}{|c|c|c|c|c|c|}
\hline \multirow{2}{*}{\multicolumn{2}{|c|}{$\frac{\text { Entry }}{\text { 2-HYDROXY SPHINGOLIPIDS SP (2OH) }}$}} & \multirow[t]{2}{*}{ Number of samples } & \multicolumn{2}{|c|}{ Extraction Methods } & \multirow[t]{2}{*}{ Ref. } \\
\hline & & & & & \\
\hline 1 & human serum & japanese residents $(n=125)$ & $\begin{array}{l}\text { pre-extraction: } \\
\text { extraction: } \\
\text { re-dissolved: }\end{array}$ & $\begin{array}{l}\text { IS addition }+ \text { ">+ lyophilization OPE: } \\
\text { PPT: } \mathrm{CHCl}_{3} / \mathrm{MeOH}(1: 1)+\text { +>+ drying } \\
\text { MeOH }\end{array}$ & [31] \\
\hline 2 & $\begin{array}{l}\text { brain tissue } \\
\text { blood }\end{array}$ & $\begin{array}{l}\text { control }(n=14) \text {, Alzheimer disease }(A D) \\
(n=15), \text { asymptomatic } A D(n=15)\end{array}$ & $\begin{array}{l}\text { homogenization: } \\
\text { analysis: }\end{array}$ & $\begin{array}{l}\text { tissue homogenizer } \\
\text { (EtOH/phosphate buffer) + sonication } \\
\text { AbsoluteIDQ® p180 kit (Biocrates Life Sciences AG) }\end{array}$ & [19] \\
\hline 3 & human serum & patients following cardiac arrest $(\mathrm{n}=290)$ & analysis: & AbsoluteIDQ ${ }^{\circledR}$ p180 kit (Biocrates Life Sciences AG) & [32] \\
\hline 4 & $\begin{array}{l}\text { cholangiocarcinoma tumor (CCA) } \\
\text { adjacent normal liver tissue }\end{array}$ & $\begin{array}{l}\text { pairs of CCA } \\
\text { adjacent normal liver tissues }(\mathrm{n}=18)\end{array}$ & $\begin{array}{l}\text { homogenization: } \\
\text { extraction: } \\
\text { re-dissolved: }\end{array}$ & $\begin{array}{l}\text { Minced + vortex }\left(\mathrm{CHCl}_{3} / \mathrm{MeOH}(1: 1)\right) \\
\text { LLE: partition: Folch method + drying } \\
\mathrm{CHCl}_{3} / \mathrm{MeOH}(2: 1)\end{array}$ & [33] \\
\hline \multicolumn{6}{|c|}{ 3-HYDROXY and DICARBOXYLIC CARNITINES CAR (3OH) and CAR (DC) } \\
\hline 5 & $\begin{array}{l}\text { mice plasma } \\
\text { liver tissue }\end{array}$ & $\begin{array}{l}\text { C57BL6/N mice }- \text { STZ }(n=10) \\
\text { control mice }(n=10)\end{array}$ & $\begin{array}{l}\text { homogenization: } \\
\text { extraction: } \\
\text { derivatization: } \\
\text { re-dissolved: }\end{array}$ & $\begin{array}{l}\text { mortar } \\
\text { OPE: PPT: MeOH to butyl esters } \\
\text { MeOH/ } \mathrm{H}_{2} \mathrm{O}\end{array}$ & [34] \\
\hline 6 & $\begin{array}{l}\text { mice plasma } \\
\text { urine }\end{array}$ & $\begin{array}{l}\text { C57BL/KsJ db/db mice T2DM }(\mathrm{n}=8) \\
\text { control } \mathrm{db} / \mathrm{m}+\text { mice }(\mathrm{n}=9)\end{array}$ & extraction: & OPE: PPT: $\mathrm{MeOH}$ & [21] \\
\hline 7 & $\begin{array}{l}\text { human plasma } \\
\text { human urine } \\
\text { rat liver tissue }\end{array}$ & $\begin{array}{l}\text { pooled plasma }(\mathrm{n}=36) \\
\text { pooled urine }(\mathrm{n}=24) \\
\text { rat liver tissue }(\mathrm{n}=1)\end{array}$ & $\begin{array}{l}\text { homogenization: } \\
\text { extraction: } \\
\text { re-dissolved: }\end{array}$ & $\begin{array}{l}\text { tissue homogenizer } \\
\text { OPE: PPT: ACN plasma/urine; } \mathrm{MeOH} \text { tissue } \\
\text { ACN }\end{array}$ & [35] \\
\hline 8 & $\begin{array}{l}\text { human plasma/serum } \\
\text { rat/mouse plasma } \\
\text { NIST SRM } ₫ 1950 \text { plasma }\end{array}$ & $\begin{array}{l}\text { plasma/serum }(\mathrm{n}=12) \\
\text { rat/mouse pooled } \\
\text { plasma NIST plasma SRM }\end{array}$ & $\begin{array}{l}\text { extraction: } \\
\text { analysis: }\end{array}$ & $\begin{array}{l}\text { OPE: PPT: } \mathrm{MeOH}+\mathrm{AA} \\
\text { AbsoluteIDQ® } 400 \mathrm{HR} \text { kit } \\
\text { (Biocrates Life Sciences AG) }\end{array}$ & [36] \\
\hline 9 & human urine & pooled NIST urine SRM $(\mathrm{n}=6)$ & $\begin{array}{l}\text { extraction: } \\
\text { re-dissolved: }\end{array}$ & $\begin{array}{l}\text { OPE: PPT: } \mathrm{MeOH} \\
\text { ACN + FA }\end{array}$ & [37] \\
\hline 10 & DBS Human & $\begin{array}{l}\text { DBS cards, base pool }(\mathrm{n}=1) \\
\text { enriched base pool }(\mathrm{n}=3)\end{array}$ & $\begin{array}{l}\text { extraction: } \\
\text { re-dissolved: }\end{array}$ & $\begin{array}{l}\text { OPE: PPT: } \mathrm{ACN} / \mathrm{H}_{2} \mathrm{O}+\mathrm{FA}+\text { hydrazine hydrate } \\
\mathrm{ACN} / \mathrm{H}_{2} \mathrm{O}+\mathrm{FA}\end{array}$ & [20] \\
\hline 11 & $\begin{array}{l}\text { rat plasma } \\
\text { urine } \\
\text { skeletal muscle }\end{array}$ & diabetic rat $(n=1)$ & $\begin{array}{l}\text { homogenization: } \\
\text { extraction: } \\
\text { derivatization: }\end{array}$ & $\begin{array}{l}\text { tissue homogenizer; } \mathrm{ACN} / \mathrm{iPrOH}+\mathrm{KH}_{2} \mathrm{PO}_{4} \\
\text { OPE: PPT: ACN } / \mathrm{H}_{2} \mathrm{O} / \mathrm{FA}+\mathrm{SPE}(\mathrm{Oasis} \mathrm{MCX}) \\
\text { to pentafluorophenacyl esters }\end{array}$ & [38] \\
\hline 12 & $\begin{array}{l}\text { mice brain, heart, liver, } \\
\text { visceral fat, thigh muscle, } \\
\text { blood/serum }\end{array}$ & WT C57 BL5/7 mice $(\mathrm{n}=2)$ & $\begin{array}{l}\text { homogenization: } \\
\text { extraction: } \\
\text { derivatization: } \\
\text { re-dissolved: }\end{array}$ & $\begin{array}{l}\text { tissue homogenizer } \\
\text { OPE: PPT: } \mathrm{MeOH} / \mathrm{H}_{2} \mathrm{O} \text { by }[13 \mathrm{C} 6] 3 \text {-nitrophenylhydrazine } \\
\text { ([13C6]-3NPH) } \\
\mathrm{H}_{2} \mathrm{O}\end{array}$ & [39] \\
\hline
\end{tabular}

OPE: One phase extraction; PPT: Protein precipitation treatment; $\mathrm{CHCl}_{3}$ : Chloroform; $\mathrm{MeOH}$ : Methanol; EtOH: Ethanol; $\mathrm{H}_{2} \mathrm{O}$ : Water; $\mathrm{ACN}$ : acetonitrile; $i$ PrOH: Isopropanol; $\mathrm{AA}$ : acetic acid; FA: formic acid; $\mathrm{KH} \mathrm{H}_{2} \mathrm{PO}$ : Monopotassium phosphate; LLE: liquid-liquid extraction; Folch method $\left(\mathrm{CHCl}_{3} / \mathrm{MeOH}(2: 1)\right.$; SPE: Solid phase extraction. For a comprehensive list of abbreviations refer to the Supplementary excel. 
Table 1.2

SAMPLE PREPARATION - CLASS II - Oxygenated lipid containing polyunsaturated fatty acids (PUFAs) peroxidation products.

\begin{tabular}{|c|c|c|}
\hline Entry & Biological sample & Number of samples/Collection/Storage \\
\hline OXIDI & YCEROPHOSPHOLII & XXPE, OXPC, OXPS, OXPG, OXPI, OXPA \\
\hline
\end{tabular}

$13 \quad$ human plasma

human serum

mice lung tissue

human plasma

adipose

lean/obese mice

human platelets

mouse pancreatic islets

dry blood spots

human plasma

HeLa cells hypertension patients $(\mathrm{n}=73)$

Extraction Methods

Alzheimer's disease $(\mathrm{n}=21)$ healthy volunteers $(\mathrm{n}=16)$

young (2-4 month old)/aging (18-24 month old) mice under basal conditions/inflammatory insult ( $\mathrm{n}=4$ ) group)

controls $(\mathrm{n}=59)$

$\mathrm{CDK}(\mathrm{n}=13)$

CDK + periodontitis $(n=20)$ periodontitis $(n=17)$

healthy volunteers $(n=20)$

lean mice and mice fed HFD ( $n \geq 4$ /group)

IS: extraction 1:

extraction 2 :

re-dissolved:

extraction 1:

IS: extraction 2:

re-dissolved:

extraction 1:

IS:extraction 2:

re-dissolved:

re-dissolved

extraction 1:

IS: extraction 2:

re-dissolved:

extraction 1:

IS: extraction 2:

re-dissolved:

IS: extraction 2:

stable angina pectoris $(\mathrm{n}=10)$

ST-elevation myocardial infarction $(\mathrm{n}=13)$

$3 \times 10^{8}$ platelets/sample/controls $(\mathrm{n}=11)$

mouse $(\mathrm{n}=1)$

tissue sections $(\mathrm{n}=14)$

MCADD $(n=25) /$ controls $(n=25)$

Validation cohort:

MCADD $(n=25) /$ controls $(n=250)$

non-pancreatic neuroendocrine tumor $(\mathrm{n}=77)$

healthy controls $(\mathrm{n}=68)$

healthy non-smoking $\operatorname{BAL}(\mathrm{n}=8)$ pre-extraction:

extraction:

IS: re-dissolved:

extraction:

IS: re-dissolved:

nano-DESI:

IS:

extraction:

extraction 1:

extraction 2:

extraction 3 :

IS: re-dissolved:

pre-extraction:

is: extraction: 1 :

15. extraction $1:$

extraction 2:

re-dissolved:

pre-extraction:

IS: extraction:

re-dissolved:
PC 12:0/12:0, PS 12:0/12:0 modified Folch method:

lipoprotein fraction $+\mathrm{MTBE} / \mathrm{MeOH}$

[40]

aqueos layer $+\mathrm{MTBE}(\mathrm{x} 2)$; mix organic phases +

drying under $\mathrm{N}_{2} \mathrm{CHCl}_{3} / \mathrm{MeOH} / \mathrm{H}_{2} \mathrm{O}(2 \cdot 7: 1)$

diluted in $\mathrm{ACN} / \mathrm{H}_{2} \mathrm{O}$ (1:9)

modified Matyash method: $\mathrm{MeOH} / \mathrm{BHT} / \mathrm{MTBE} / \mathrm{H}_{2} \mathrm{O}$

[D31]POPC-(PC(16:0-[D31]/18:1))

$\mathrm{MeOH} / \mathrm{MTBE} / \mathrm{H} 2 \mathrm{O}+$ drying in vacuum

$\mathrm{MeOH}$

$\mathrm{MeOH} / \mathrm{AA} / \mathrm{BHT}$

DNPC + odd-numbered PC 13:0/13:0 washing (x3)

hexane/BHT/ $\mathrm{CHCl}_{3} / \mathrm{FA}+$ drying under $\mathrm{Ar}$

$\mathrm{CHCl}_{3}+$ drying under Ar aqueous $\mathrm{MeOH} / \mathrm{AF}+\mathrm{FA}$

$\mathrm{MeOH} / \mathrm{AA} / \mathrm{BHT}$

DMPC + DNPC washing (x3) hexane/BHT/ $\mathrm{CHCl}_{3} / \mathrm{FA}+$

drying under Ar

aqueous $\mathrm{MeOH} / \mathrm{AF} / \mathrm{FA}$

modified Matyash method: $\mathrm{MeOH} / \mathrm{MTBE} / \mathrm{H}_{2} \mathrm{O}$

[D54]DMPC-MeOH/MTBE/ $\mathrm{H}_{2} \mathrm{O}+$ drying in vacuum

$\mathrm{MeOH}$

$\mathrm{CHCl}_{3} / \mathrm{MeOH} / \mathrm{BHT} / \mathrm{H}_{2} \mathrm{O}$

DNPC aqueos fraction $+\mathrm{CHCl}_{3}$; organic layers

mixture + drying under $\mathrm{Ar}$

$\mathrm{H}_{2} \mathrm{O} / \mathrm{MeOH}+\mathrm{AA}$

citrate-dextrose buffer/light protection

cold acidic EtOH + sonication + drying under $\mathrm{N}_{2}$

odd-numbered mixture: LPC 17:1/0:0, PC 17:0/20:4

$\mathrm{MeOH}$

modified Folch method; organic phase + dryin

LPC 19:0/0:0, [D8]FA 20:4

$\mathrm{CHCl}_{3} / \mathrm{MeOH}(1: 9)$ no treatmen

$\mathrm{MeOH} / \mathrm{H}_{2} \mathrm{O}(2: 1)$

PG-PC, PAz-PC

$\mathrm{MeOH} / \mathrm{EtOH}(1: 1)$

$\mathrm{MTBE} / \mathrm{MeOH} / \mathrm{H}_{2} \mathrm{O} i \mathrm{PrOH} / \mathrm{H}_{2} \mathrm{O}(75: 25, \mathrm{v} / \mathrm{v})$

iPrOH/ $\mathrm{H}_{2} \mathrm{O}(90: 10, \mathrm{v} / \mathrm{v})$

$\mathrm{CHCl}_{3} / \mathrm{MeOH} / \mathrm{H}_{2} \mathrm{O}$

Avanti's SPLASH ${ }^{\mathrm{TM}}$ LIPIDOMIX

$\mathrm{MeOH}$

ozone exposure (60, 150, $300 \mathrm{ppb}, 60 \mathrm{~min})$

LPC 16:0 [D31]/0:0 option 1 -

methoxylamine + lipid extraction

option 2 - modified Bligh-Dyer

untreated derivatized samples $+\mathrm{MeOH} / \mathrm{CH}_{2} \mathrm{Cl}_{2}$

aqueous layer $+\mathrm{CHCl}_{3}$

organic phases mixture + drying under $\mathrm{N}_{2}$

$\mathrm{MeOH} / \mathrm{ACN} / \mathrm{H}_{2} \mathrm{O}+\mathrm{AA}$

Cells treated with $\mathrm{H}_{2} \mathrm{O}_{2}$, fractionated

using AF4 odd-numbered fatty acyl chain mixture

$\mathrm{MeOH} / \mathrm{MTBE} / \mathrm{H}_{2} \mathrm{O}(3: 10: 2.5)$ aqueos

layer re-extracted (x2) with MeOH:MTBE +

drying under $\mathrm{N}_{2}$

$\mathrm{CHCl}_{3} / \mathrm{MeOH}(1: 9)+$ diluted with $\mathrm{MeOH}: \mathrm{H}_{2} \mathrm{O}(8: 2)$

(continued on next page) 
Table 1.2 (continued)

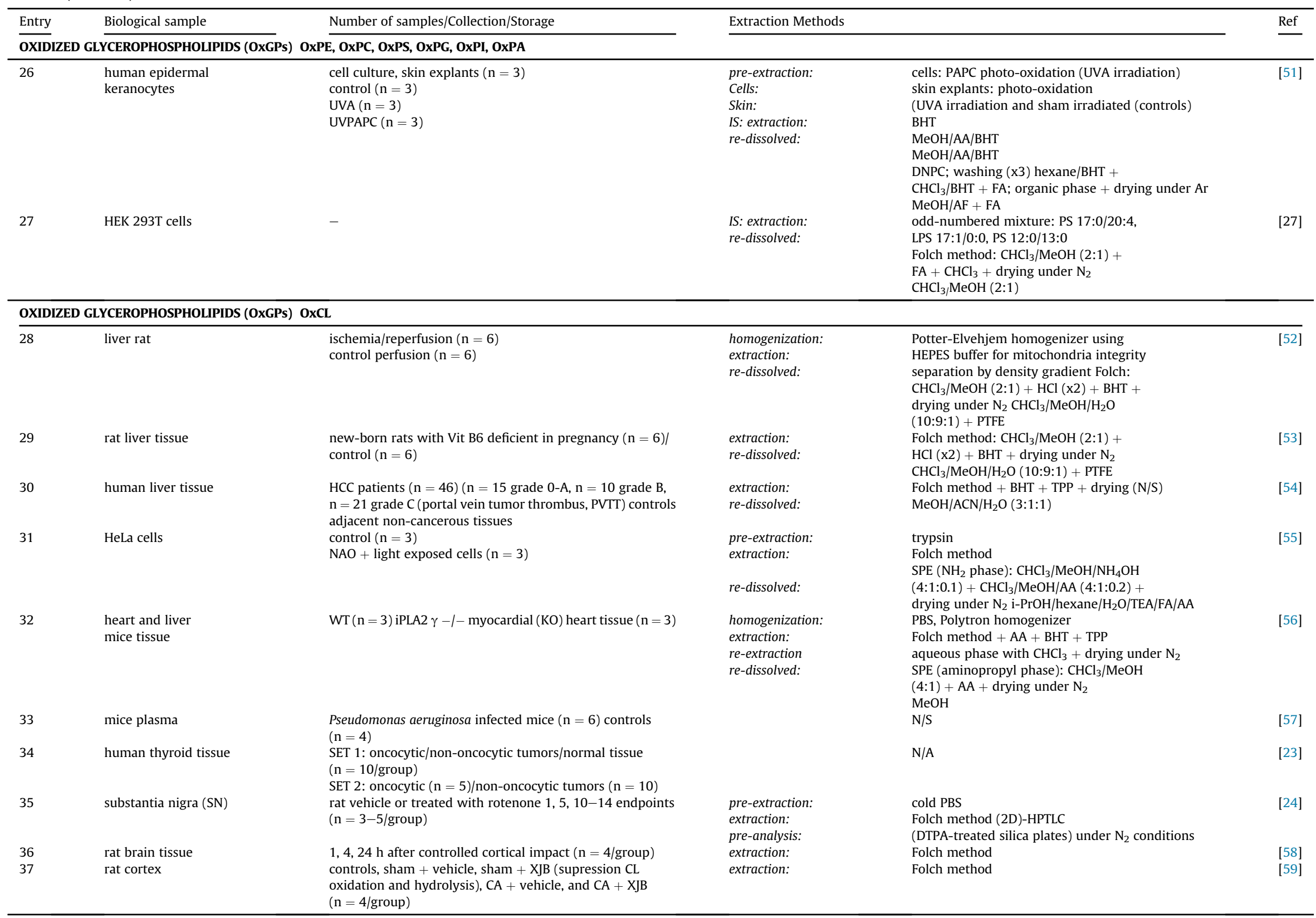




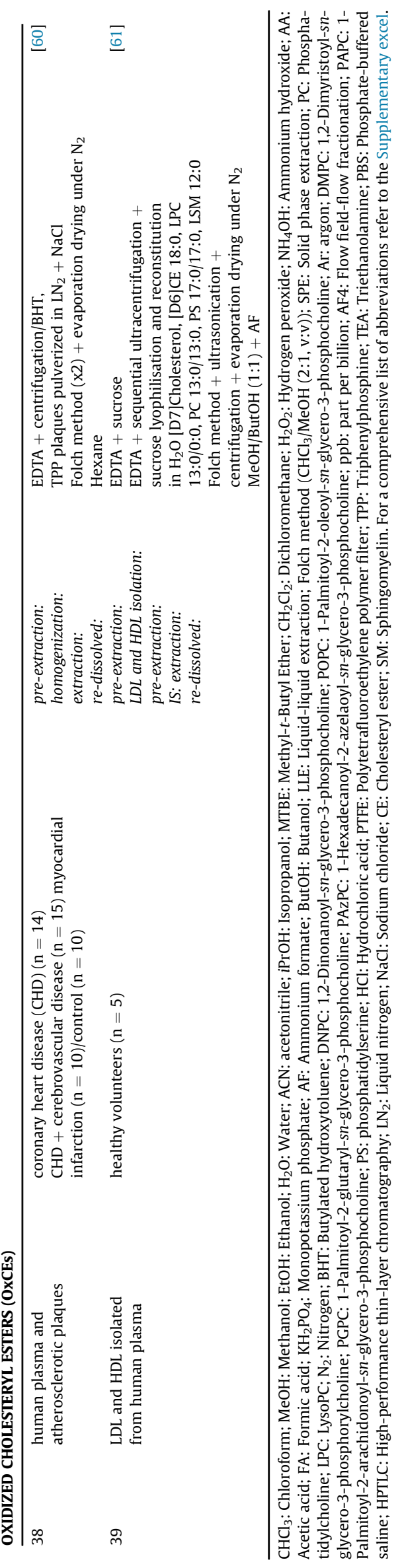

species (ROS) [76]. The general oxidation mechanisms and the central biological activities of OxGPs are already well-documented and extensively reviewed [15]. In the case of CLs, the oxidation is mainly carried out enzymatically by cytochrome $c$, which presents a marked selectivity, in terms of lipid class (CLs vs other GP classes) and within the CL species since the C18:2 residue (TLCL) is its mayor oxidation target even in the presence of molecular species that are more readily "oxidizable" [77]. In the case of OxCEs, they are produced in the context of oxidation of LDL to OxLDL and may be produced by enzymatic (i.e. by 12/15-lipoxygenase) or ROS mechanisms [17,75]. Although OxCEs are likely to be very similar to OxGPs, there are fewer studies, in part because they reside inside the hydrophobic core of LDL and are presumably exposed to a different oxidative environment in vivo, in addition to difficulties in their analysis which will be discussed in section $4[8,17]$. The extensive variety of possible products for both groups includes full-length and chain-shortened oxidation products, and the corresponding fragments of the oxidized fatty acid chains. The full-length oxidation products vary from simple modification (hydroperoxides, hydroxides, epoxides, and ketones) to more complex products such as those resulting from cyclization or further rearrangements [14-16,78] (Supporting Tables S4.1-S4.3).

\subsection{Class III. Oxygenated lipids derived from cholesterol peroxidation. Oxysterols}

Finally, oxysterols are compounds from cholesterol metabolism that present oxygenated functional groups in the sterol ring and/or in the side chain. They are metabolic intermediates in bile acid and steroid hormone synthesis pathways, as well as very important bioactive molecules in a multitude of processes such as cholesterol metabolism in the brain, embryonic development, and the progression of different pathologies - i.e. cerebrotendinous xanthomatosis (CTX) and hereditary spastic paraplegia type 5 (SPG5) $[79,80]$. Their pathophysiological role has brought attention to the possibility of monitoring them as biomarkers, which is discussed further in section 5 [18].

As OxGPs and OxCEs, oxysterols can be formed by enzymatic or auto-oxidation mechanisms. The former is mainly produced in biosynthetic pathways [80], while the latter may be produced in the context of oxidative stress [65,81,82].

From now on, highlights of the study of these oxygenated lipids will be discussed in the following sections of sample preparation, LC-MS approaches and biomarker candidate findings.

\section{Sample preparation}

Analysis of oxidized lipids (classes II and III), especially peroxides, is a challenging task in MS due to their high chemical and thermal instability, and the potential for further propagation of lipid oxidation and eventual degradation. On top of that is the fact that their non-oxidized precursors can be readily oxidized by the air, light, or metal ions, generating higher levels of these compounds ex vivo during sample handling as has been reported for OxGPs and oxysterols [79,83].

Although sample processing is probably the most critical step to ensure reliable data collection, there is a lack of research studies examining the influence of this step for the analysis of the oxygenated lipid classes covered by this review (Fig. 1).

To date, the evidences presented in Tables 1.1-1.3 show that the steps in sample treatment for oxygenated lipids follow the classical lipidome workflow. Nevertheless, we have highlighted below the most relevant aspects observed, which include both native and oxygenated lipids. 
Table 1.3

CLASS III - SAMPLE PREPARATION - Oxygenated derivatives biomarkers of cholesterol peroxidation (oxysterols).

\begin{tabular}{|c|c|c|c|c|c|}
\hline \multirow{2}{*}{$\frac{\text { Entry }}{\text { STERO }}$} & \multirow{2}{*}{$\frac{\text { Biological Samples }}{\text { OXYSTEROLS }}$} & \multirow[t]{2}{*}{ Number of samples } & \multicolumn{2}{|l|}{ Extraction Methods } & \multirow[t]{2}{*}{ Ref. } \\
\hline & & & & & \\
\hline & $\begin{array}{l}\text { human plasma } \\
\text { carotid plaques }\end{array}$ & $\begin{array}{l}\text { men }(\mathrm{n}=45) / \text { women }(\mathrm{n}=18) \\
\text { undergoing carotid endarterectomy: } \\
\text { symptomatic }(\mathrm{n}=29) \\
\text { asymptomatic }(\mathrm{n}=34)\end{array}$ & $\begin{array}{l}\text { pre-extraction conditions: } \\
\text { plaque pre-extraction: } \\
\text { re-dissolved: } \\
\text { plaque }+>+ \\
\text { plasma extraction: } \\
\text { re-dissolved: }\end{array}$ & 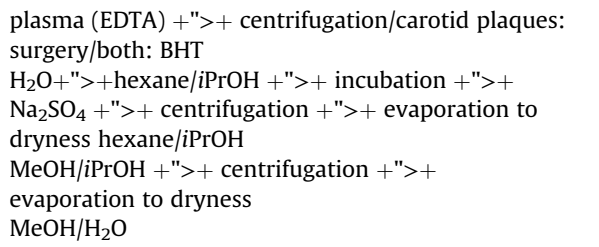 & [62] \\
\hline 41 & $\begin{array}{l}\text { mice plasma } \\
\text { mice liver tissue }\end{array}$ & $\begin{array}{l}\text { acute liver injury }(\mathrm{n}=8) \\
\text { controls }(\mathrm{n}=8)\end{array}$ & $\begin{array}{l}\text { pre-extraction additives: } \\
\text { tissue homogenization: } \\
\text { plasma extraction: } \\
\text { re-dissolved: }\end{array}$ & $\begin{array}{l}\text { BHT } \\
\text { MeOH/ } / \mathrm{H}_{2} \mathrm{O} \text {, Tissue homogenizer }+ \text { ultrasonication }+ \\
\text { incubation }-20^{\circ} \mathrm{C}+\text { centrifugation } \\
\text { MeOH/CH} / \mathrm{CH}_{2} \mathrm{Cl}_{2}+\text { ultrasonication }+ \text { incubation }-20^{\circ} \mathrm{C}+ \\
\text { centrifugation }+ \text { drying under } \mathrm{N}_{2} \\
\mathrm{MeOH} / \mathrm{H}_{2} \mathrm{O}\end{array}$ & [63] \\
\hline 42 & $\begin{array}{l}\text { human serum } \\
\text { plasma } \\
\text { CSF }\end{array}$ & $\begin{array}{l}\text { serum/CSF: } \\
\text { with BBB disturbance }(\mathrm{n}=3) / \\
\text { without }(\mathrm{n}=3) \\
\text { plasma: } \\
\text { healthy men }(\mathrm{n}=56) / \text { women }(\mathrm{n}=44)\end{array}$ & $\begin{array}{l}\text { pre-extraction conditions: } \\
\text { extraction: }\end{array}$ & $\begin{array}{l}\text { plasma (EDTA) + centrifugation/BHT } \\
i \text { PrOH + on-line SPE (Strata-X } 25 \mu \mathrm{m})\end{array}$ & [64] \\
\hline 43 & human plasma & $\begin{array}{l}\text { Niemann-Pick diseases } \\
\text { (NPC and NPB; } n=3 \text { /group) } \\
\text { lysosomal acid lipase deficiency } \\
(\text { LALD; } n=2) \text {, carriers }(n=5)\end{array}$ & $\begin{array}{l}\text { extraction: } \\
\text { derivatization: }\end{array}$ & $\begin{array}{l}\text { EtOH + ultrasonication }+ \text { SPE (Sep-Pak C18) } \\
\text { EADSA: oxidation with bacterial cholesterol } \\
\text { oxidase }+\left[{ }^{2} \mathrm{H}_{5}\right] \text {-labeled Girard P reagent }\end{array}$ & [65] \\
\hline 44 & $\begin{array}{l}\text { mice plasma } \\
\text { mice colon-human } \\
\text { colon biopsies }\end{array}$ & $\begin{array}{l}\text { mice: control }(\mathrm{n}=26) \\
\text { DSS-induced colitis }(\mathrm{n}=8) \\
\text { oxazolone-induced colitis }(\mathrm{n}=8) \\
\text { TNBS-induced colitis }(\mathrm{n}=10) \\
\text { humans: control }(\mathrm{n}=10) \\
\text { Crohn's }(\mathrm{n}=5) \text {; ulcerative colitis }(\mathrm{n}=5)\end{array}$ & $\begin{array}{l}\text { pre-extraction additives: } \\
\text { homogenization: } \\
\text { extraction: }\end{array}$ & $\begin{array}{l}\text { BHT + EDTA glass vial } / \mathrm{CH}_{2} \mathrm{Cl}_{2} \\
\text { LLE: MeOH and bi-distilled } \mathrm{H}_{2} \mathrm{O}+\text { sonication }+ \\
\text { drying under } \mathrm{N}_{2} \\
+ \text { SPE: over silica using hexane/iPrOH }\end{array}$ & [66] \\
\hline 45 & $\begin{array}{l}\text { human plasma } \\
\text { RBCs }\end{array}$ & $\begin{array}{l}\text { healthy }(\mathrm{n}=32) \\
\text { NPC }(\mathrm{n}=4 \text { disease }+ \text { family members }) \\
\text { CTX }(\mathrm{n}=2)\end{array}$ & $\begin{array}{l}\text { pre-extraction conditions: } \\
\text { alkaline hydrolysis: } \\
\text { extraction: } \\
\text { derivatization: } \\
\text { re-dissolved: }\end{array}$ & $\begin{array}{l}\text { plasma }(\mathrm{EDTA})+\text { centrifugation/RBCs: centrifugation, } \\
\text { separation }+ \text { wash } \mathrm{NaCl} / \mathrm{BHT} \\
\mathrm{KOH} \text { in EtOH } \\
\mathrm{NaCl}+\text { isooctane }+ \text { centrifugation } \\
\text { DMG, DMAP, EDC + evaporation to dryness } \\
\mathrm{MeOH}\end{array}$ & [67] \\
\hline
\end{tabular}

ytoluene; EADSA: enzyme-assisted derivatization for sterol analysis; $\mathrm{NaCl}$ : Sodium chloride; $\mathrm{Na}_{2} \mathrm{SO}_{4}$ :Sodium sulfate. For a comprehensive list of abbreviations refer to the Supplementary excel. 
Table 2.1

CLASS I - SAMPLE ANALYSIS - Oxygenated lipids containing 2- and 3-hydroxy fatty acids.

\begin{tabular}{|c|c|c|c|c|c|c|}
\hline Entry & Separation technique & Ionization/Analysis mode & MS analyser & Standards & Analytical strategy and/or objective & Ref \\
\hline \multicolumn{7}{|c|}{ 2-HYDROXY SPHINGOLIPIDS SP (2OH) } \\
\hline \multicolumn{7}{|c|}{ Targeted } \\
\hline 1 & RPLC (C30) & N/S/MRM & QqQ & $\begin{array}{l}\text { NeuAcHex2Cer } 18: 1 ; \text { O2/[13C]16:0 } \\
\text { SM 18:1; O2/17:0 } \\
\text { Cer } 18: 1 ; \text { O2/17:0 }\end{array}$ & serum GM3 molecular profiling & [31] \\
\hline 2 & N/A- FIA & N/S/MRM & QqLIT & AbsoluteIDQ ${ }^{\circledR}$ p180 kit & blood and brain target profiling & [19] \\
\hline 3 & N/A- FIA & N/S/MRM & QqLIT & AbsoluteIDQ ${ }^{\circledR}$ p180 kit & serum SM profiling & [32] \\
\hline \multicolumn{7}{|c|}{ Untargeted $=>$ Targeted } \\
\hline 4 & RPLC (C30) & $\operatorname{ESI}( \pm)=>\operatorname{ESI}(+) / \mathrm{MRM}$ & $\mathrm{IT}-\mathrm{TOF}=>\mathrm{QqQ}$ & Lac-Cer18:1; 02/[13C]16:0 & liver sphingolipid profiling & [33] \\
\hline \multicolumn{7}{|c|}{ 3-HYDROXY and DICARBOXYLIC CARNITINES CAR (3OH) and CAR (DC) } \\
\hline \multicolumn{7}{|c|}{ Targeted } \\
\hline 5 & RPLC (C18) & $\mathrm{ESI}(+) / \mathrm{MRM}$ & QqQ & deuterated acyl-L-carnitines & method development and validation & [34] \\
\hline 6 & HILIC/RPLC (C18) & $\mathrm{ESI}(+) / \mathrm{PRM}$ & Orbitrap & deuterated acyl-L-carnitines & method development and validation & [21] \\
\hline 7 & RPLC (C18) & $\mathrm{ESI}(+) / \mathrm{PRM}$ & Orbitrap & $\begin{array}{l}\text { deuterated acyl-L-carnitines } \\
\text { including CAR-OH }\end{array}$ & method development and validation & [35] \\
\hline 8 & N/A- FIA & $\mathrm{ESI}(+) / \mathrm{MS} / \mathrm{MS}$ & Orbitrap & AbsoluteIDQ ${ }^{\circledR}$ p400 HR kit & cross-laboratory method validation & [36] \\
\hline 9 & RPLC (C18) & $\mathrm{ESI}(+) / \mathrm{MS} / \mathrm{MS}$ & Orbitrap & acyl-L-carnitines including CAR-OH & method development and validation & [37] \\
\hline 10 & N/A-DI & chip-based ESI(+)/SIM/PRM & Orbitrap & $\begin{array}{l}\text { deuterated acyl-L-carnitines } \\
\text { including CAR-OH }\end{array}$ & method development and validation & [20] \\
\hline \multicolumn{7}{|c|}{ Untargeted $=>$ Targeted } \\
\hline 11 & RPLC (C8) & $\operatorname{ESI}(+)=>\operatorname{MRM}$ & $\mathrm{QqLIT}=>\mathrm{QqQ}$ & deuterated acyl-L-carnitines & method development and validation & [38] \\
\hline 12 & RPLC (C18) & $\operatorname{ESI}(+)=>\operatorname{MRM}$ & QqLIT $=>$ Orbitrap & deuterated acyl-L-carnitines & method development and validation & [39] \\
\hline
\end{tabular}

\subsection{Pre-extraction considerations: antioxidants and internal standards}

In lipidomics, some of the general conditions of sample collection include quick freezing of tissue and cellular samples in liquid $\mathrm{N}_{2}$, sample storage at $-80^{\circ} \mathrm{C}$, short processing times, and avoidance of freeze-thaw cycles [4,41,44,53,84]. Plenty of articles have described alterations on the levels of multiple metabolites, including lipids, due to the aforementioned factors [58,84,85]. Regarding lipids and temperature, based on our experience, it is recommended to thaw at $4^{\circ} \mathrm{C}$ to minimize enzymatic degradation and to analyze at $15^{\circ} \mathrm{C}$ to avoid precipitation [86]. Furthermore, for analysis of oxygenated lipids containing PUFAs and oxysterols (classes II and III), which can be produced by oxidation of their precursors during sample preparation, antioxidants and radical scavengers such as triphenylphosphine (TPP) and butylated hydroxytoluene (BHT) are commonly used for sample storage or at the initial steps of the lipid extraction (Tables 1.2 and 1.3) $[53,84,52,54,62-64,66,67]$. Another example is addition of phenylmethanesulfonyl fluoride (PMSF) prior to sample extraction, which increases the stability of GPs and SPs by the deactivation of serine hydrolase [87]. However, the effect of antioxidants as reducing agents on other oxidized lipids, mostly in the case of TPP, has not been studied.

Anticoagulants are necessary when collecting plasma, and EDTA is the most common. This compound has the additional benefit of forming complexes with metal ions such as copper or iron, avoiding their pro-oxidative behavior. For this purpose, it can also be added in an extra step (entry 44) [66]. Other anticoagulants such as citratedextrose have been used to preserve and maintain the cellular structure as in the case of platelets (entry 19) [45].

Even though standardized protocols for blood sample collection are currently available for general lipidomics-based analysis, there is no consensus yet on which strategy is the best for oxygenated lipids in terms of pre-extraction conditions. Some studies have addressed these crucial points for the analysis of oxylipins [29,30,88,89]. Therefore, one might think that these guidelines could be extrapolated to analyze other oxygenated lipids. However, while for OxGPs the most extended advice is the addition of synthetic antioxidants such as BHT (Table 1.2) [25,56,44,53,52,54,43,42], the addition of BHT or working under nitrogen atmosphere had no protective effects for oxylipins $[30,88,89]$. Moreover, the effect of BHT in other metabolites in non-targeted approaches has not been studied. An increasing number of studies developed with multiple tissue types, biofluids and cell lines to detect oxygenated lipids, especially for OxGPs, can be found in the literature $[41,44]$. However, to our knowledge, there are no concrete guidelines for sample handling when analyzing OxGPs in tissues and cell cultures as for bloodderived samples.

Sample treatment depends on the type of sample, the analytical technique and the metabolomic approach. For the analysis of oxygenated lipids covered in this review, plasma and serum were still the most common biological matrices reported. Other types of samples included urine, tissue (brain, liver, adipose, etc.) or cells (Tables 1.1-1.3). For tissues or cells, homogenization is an important step (entries 2, 7, 11) [19,35,38]. In the case of CLs present in the inner mitochondrial membrane, the use of different buffers or sugar solutions such as sucrose is needed to maintain the mitochondrial structure in the consecutive centrifugations before metabolite extraction (Table 1.2) [52].

Other strategies to analyze specific biological populations include asymmetrical flow field-flow fractionation (AF4), which has been employed for OxGPs analysis in subcellular organelles and exosomes (entry 25) [50]. Furthermore, Lee et al. utilized the multiplexed hollow fiber flow field-flow fractionation for a semi-preparative size sorting of different lipoprotein classes, which allowed the authors to describe their lipid profile (entry 13) $[40]$.

In the case of oxysterols, another important factor is that the majority of the oxysterol content is esterified with fatty acids. Thus, some methods include an alkaline hydrolysis step to quantify the total amount of oxysterols and to improve the detection (entry 45) [67]. However, some authors argue that to get the true picture of the functional state of oxysterol metabolites one must detect the levels of free oxysterols, which are the bioactive components (entry 42) [64]. 
Table 2.2

SAMPLE ANALYSIS - CLASS II - Oxygenated lipids containing polyunsaturated fatty acids (PUFAS) peroxidation products.

\begin{tabular}{|c|c|c|c|c|c|c|}
\hline Entry & Separation technique & Ionization/Analysis mode & MS analyser & Standards ${ }^{a}$ & Analytical strategy and/or objective & Ref. \\
\hline \multicolumn{7}{|c|}{ OXIDIZED GLYCEROPHOSPHOLIPIDS (OXGPS) OXPE, OXPC, OXPS, OXPG, OXPI, OXPA } \\
\hline \multicolumn{7}{|c|}{ Targeted } \\
\hline 13 & $\mathrm{nLC}(\mathrm{C} 18)$ & $\mathrm{ESI}( \pm) / \mathrm{MS}^{\mathrm{n}}$ & QqLIT & PC $12: 0 / 12: 0$, PS $12: 0 / 12: 0$ & lipidomics profiling & {$[40]$} \\
\hline 14 & RPLC (C18) & $\mathrm{ESI}(+) / \mathrm{MRM}$ & QqLIT & POVPC, [D31]POPC & method validation & [25] \\
\hline 15 & RPLC (C18) & $\mathrm{ESI}(+) / \mathrm{MRM}$ & QqLIT & $\begin{array}{l}\text { POVPC, PGPC, PAzPC, PONPC, } \\
\text { KOdiAPC }\end{array}$ & biological role discovery of OxGPs & [41] \\
\hline 16 & RPLC (C18) & $\operatorname{ESI}( \pm) / \mathrm{SRM}$ & QqLIT & POVPC, PGPC, PAzPC, PONPC & MS vs. immune assays for OxPC analysis & [42] \\
\hline 17 & RPLC (C18) & $\mathrm{ESI}(+) / \mathrm{MRM}$ & QqLIT & $\begin{array}{l}\text { POVPC, PGPC, PAzPC, PONPC } \\
\text { OxSAPC, OxSLPC via } \mathrm{Fe}(\mathrm{II}) / \mathrm{H}_{2} \mathrm{O}_{2}\end{array}$ & method validation & [43] \\
\hline 18 & RPLC (C18) & $\mathrm{ESI}(+) / \mathrm{MRM}$ & QTRAP & OxPAPC, OxPLPC via air oxidation & biological role discovery of OxGPs & [44] \\
\hline 19 & RPLC (C8) & $\mathrm{ESI}(+) / \mathrm{MS} / \mathrm{MS}$ & QTOF & POVPC, PGPC, PAzPC, PONPC & biological role discovery of OxGPs & [45] \\
\hline \multirow[t]{2}{*}{20} & MSI: N/A & nano-DESI $( \pm)$ & Orbitrap & LPC19:0/0:0 and [D8]FA 20:4 & method application & [46] \\
\hline & RPLC (C18) & $\mathrm{ESI}( \pm) / \mathrm{DDA}$ & & & & \\
\hline \multicolumn{7}{|c|}{ Untargeted $=>$ Targeted } \\
\hline 21 & NP (amino-propyl) & $\begin{array}{l}\mathrm{ESI}(+) / \text { full scan }+ \\
\mathrm{ESI}( \pm) / \mathrm{MS}^{\mathrm{n}} / \mathrm{FIA} / \mathrm{MRM}\end{array}$ & $\begin{array}{l}\text { Orbitrap + } \\
\text { Orbitrap-FT/MS/QqQ }\end{array}$ & PGPC, PAzPC & biomarkers validated in a second cohort & [47] \\
\hline 22 & RPLC (C18) & $\begin{array}{l}\mathrm{ESI}( \pm) / \mathrm{MS} \\
\mathrm{ESI}( \pm) / \mathrm{MS} / \mathrm{MS}\end{array}$ & QTOF & $\mathrm{N} / \mathrm{A}$ & biological role discovery of OxGPs & [26] \\
\hline \multicolumn{7}{|c|}{ Untargeted } \\
\hline 23 & RPLC (C18) & $\mathrm{ESI}( \pm) / \mathrm{MS} ; \mathrm{MS} / \mathrm{MS}$ SWATH & QTOF & SPLASH $^{\mathrm{TM}}$ LIPIDOMIX ${ }^{\circledR}$ & method development & [48] \\
\hline 24 & RPLC (C18) & $\mathrm{ESI}( \pm) / \mathrm{MS} ; \mathrm{MS} / \mathrm{MS}$ & QqQ & LPC [31D]16:0/0:0 & OxPC identification & [49] \\
\hline 25 & $\mathrm{nLC}(\mathrm{C} 18)$ & $\mathrm{ESI}( \pm) / \mathrm{MS} / \mathrm{MS}$ & QqLIT & $\begin{array}{l}15 \text { odd-numbered fatty } \\
\text { acyl chain mixture }\end{array}$ & method development & {$[50]$} \\
\hline \multicolumn{7}{|c|}{ Semi-Targeted $=>$ Targeted } \\
\hline 26 & RPLC (C18) & $\begin{array}{l}\mathrm{ESI}(+) / \mathrm{SRM} / \mathrm{ESI}( \pm) / \\
\mathrm{MS} / \mathrm{MS} \text { PIS }\end{array}$ & QqLIT & $\begin{array}{l}\text { PAPC, PLPC, SAPC, SLPC } \\
\text { OxPAPC via UVA irradation }\end{array}$ & biological role discovery of OxGPs & {$[51]$} \\
\hline 27 & RPLC (C18) & $\mathrm{ESI}(-) / \mathrm{MS} / \mathrm{MS}, \mathrm{MRM}$ & QTOF & OxPS 18:0/18:1 via $\mathrm{Fe}(\mathrm{II}) / \mathrm{H}_{2} \mathrm{O}_{2}$ & biological role discovery of OxGPs & {$[27]$} \\
\hline \multicolumn{7}{|c|}{ OXIDIZED GLYCEROPHOSPHOLIPIDS (oxGPS) Oxidized CARDIOLIPINS (OxCLS) } \\
\hline \multicolumn{7}{|c|}{ Targeted } \\
\hline 28 & NPLC & $\mathrm{ESI}(-) / \mathrm{SRM}$ & QqQ & TMCL & biological role discovery of OxCLs & [52] \\
\hline 29 & RPLC (C18) & ESI(-)/MS/MS; SRM & QqQ & $\mathrm{N} / \mathrm{A}$ & biological role discovery of OxCLs & [53] \\
\hline 30 & $\mathrm{~N} / \mathrm{S}$ & $\mathrm{ESI}(-) / \mathrm{MS} ; \mathrm{MRM}$ & $\mathrm{QqQ}$ & TMCL & biological role discovery of OxCLs & [54] \\
\hline \multicolumn{7}{|c|}{ Untargeted $=>$ Targeted } \\
\hline 31 & RPLC (C8) & $\mathrm{ESI}(-) / \mathrm{SRM}$ & LIT & $\mathrm{N} / \mathrm{A}$ & Biological role of OxCLs & [55] \\
\hline 32 & RPLC (C18) & ESI(-)/MS/MS; SRM & Orbitrap & TMCL & biological role discovery of OxCLs & [56] \\
\hline \multicolumn{7}{|c|}{ Untargeted } \\
\hline 33 & NPLC & $\mathrm{ESI}(-) / \mathrm{MS} / \mathrm{MS}$ & LIT & $\mathrm{N} / \mathrm{A}$ & total content of OxCLs & [57] \\
\hline 34 & NPLC & DESI(-)/MS; MS/MS & Orbitrap & $\mathrm{N} / \mathrm{A}$ & Biological role of OxCLs & [23] \\
\hline 35 & 2D-HPTLC + RPLC (C8) & $\mathrm{ESI}(-) / \mathrm{MS} ; \mathrm{MS} / \mathrm{MS}$ & Orbitrap & $\begin{array}{l}\text { TMCL (internal standard) } \\
\text { TLCL (external standard) }\end{array}$ & biological role discovery of OxCLs & [24] \\
\hline 36 & RPLC (C18) & $\mathrm{ESI}(-), \mathrm{MS} ; \mathrm{DDA}$ & Orbitrap & TLCL & biological role discovery of OxCLs & [58] \\
\hline 37 & $\mathrm{~N} / \mathrm{S}$ & $\mathrm{ESI}(-) / \mathrm{MS} ; \mathrm{MS} / \mathrm{MS}$ & Orbitrap & $\mathrm{N} / \mathrm{A}$ & biological role discovery of OxCLs & [59] \\
\hline \multicolumn{7}{|c|}{ OXIDIZED CHOLESTERYL ESTERS (OXCES) } \\
\hline \multicolumn{7}{|c|}{ Targeted } \\
\hline 38 & NPLC & $\mathrm{ESI}(+) / \mathrm{MRM}$ & QqQ & $\begin{array}{l}\text { oxLA-CEs, oxAA-CEs via } \\
\text { azo-initiated peroxidation }\end{array}$ & $\begin{array}{l}\text { method development and application } \\
\text { to the study of CVD }\end{array}$ & [60] \\
\hline \multicolumn{7}{|c|}{ Untargeted $=>$ Targeted } \\
\hline 39 & RPLC (C18) & $\mathrm{ESI}(+)=>\operatorname{ESI}(+) / \mathrm{MRM}$ & $\mathrm{QTOF}=>$ QqLIT & $\begin{array}{l}\text { deuterated IS for oxysterols } \\
\text { (cholesterol-d7 and 7-KC-d7) }\end{array}$ & $\begin{array}{l}\text { method development and application } \\
\text { to the study of OxLDL }\end{array}$ & [61] \\
\hline
\end{tabular}

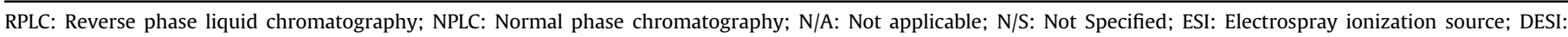

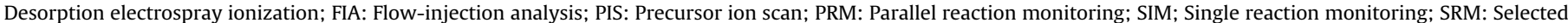

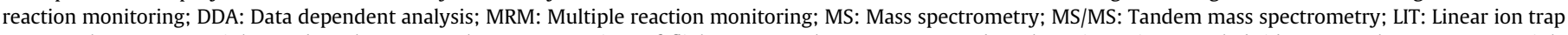

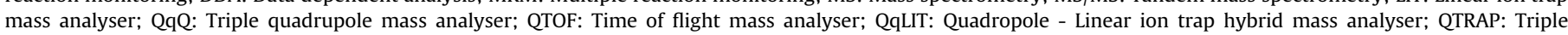
Quadrupole Linear Ion Trap; IT-TOF: Ion trap - Time of flight hybrid mass analyser. For a comprehensive list of abbreviations refer to the Supplementary excel.

a Refer to Supporting Information for full abbreviations of standards.

Due to the low abundance of oxygenated lipids, the extraction of these metabolites from biological matrices is not always constant due to laborious procedures, and variations of final recoveries can take place, especially when several extraction steps are required. Therefore, the use of internal standards (IS) is unquestionably required, as for any quantitative lipidomics-based analysis.

IS are added to the sample before the extraction to normalize the extraction efficiency and instrumental response. They are usually synthetic and contain saturated fatty acids [90,91], either evennumber chains such as 1,2-dimyristoyl-sn-glycero-3-phosphoryl- choline (DMPC) (entry 16) [42] or odd-number chains (C 13:0, C $17: 0$, C 19:0) (entry 39) [61] such as 1,2-dinonanoyl-sn-glycero-3phosphocholine (DNPC) (entries 15, 16, 18, 26) [41,42,44,51]. Stable isotope-labeled lipids are also routinely used: [D31]LPC 16:0 (entry 24) [49], [D6]DNPC (entries 14, 17, 20, 24) [25,43,49,46]. Commercial mixtures of deuterated standards solutions such as Avanti SPLASH ${ }^{\mathrm{TM}}$ LIPIDOMIX® (entry 23) [48] are also available, among other suppliers. All of these are non-oxidized lipid standards. Regarding structural characterization or identification of oxygenated lipids, other standards, including oxidized ones, are used and are commented in the LC-MS analysis section 4.1.1. 
Table 2.3

CLASS III - SAMPLE ANALYSIS - Oxygenated lipids derived from cholesterol peroxidation (oxysterols).

\begin{tabular}{|c|c|c|c|c|c|c|}
\hline Entry & Separation technique & Ionization/Analysis mode & MS analyser & Standards & Analytical strategy and/or objective ${ }^{a}$ & Ref. \\
\hline \multicolumn{7}{|c|}{ OXYSTEROLS } \\
\hline \multicolumn{7}{|c|}{ Targeted } \\
\hline 40 & RPLC (C18) & $\mathrm{APCI}(+) / \mathrm{MRM}$ & QqQ & deuterated IS & method application to study carotid artery stenosis & [62] \\
\hline 41 & RPLC (C8) & $\mathrm{ESI}( \pm) / \mathrm{MRM}$ & QqQ & deuterated IS & method development and validation & [63] \\
\hline 42 & RPLC (C18) & $\mathrm{ESI}( \pm) / \mathrm{MRM}$ & QqLIT & deuterated IS & method development and validation & [64] \\
\hline 43 & RPLC (C18) & $\mathrm{ESI}(+) / \mathrm{PRM}$ & Orbitrap & deuterated IS & $\begin{array}{l}\text { method application to analyze the metabolism } \\
\text { of 7-KC and C-triol }\end{array}$ & [65] \\
\hline 44 & RPLC (C18) & $\mathrm{APCI}(+) / \mathrm{N} / \mathrm{S}$ & Orbitrap & deuterated IS & method application to study IBD & [66] \\
\hline 45 & RPLC (biphenyl) & $\mathrm{ESI}(+) / \mathrm{PRM}$ & Orbitrap & deuterated IS & method development and validation & [67] \\
\hline
\end{tabular}

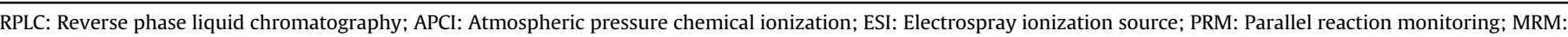

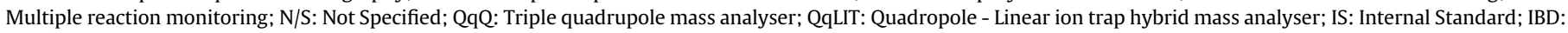
Inflammatory bowel disease. For a comprehensive list of abbreviations refer to the Supplementary excel.

a Refer to Supporting Information for full abbreviations.

\subsection{Extraction and concentration methods: protein precipitation,} liquid-liquid extraction, solid phase extraction and solid phase microextraction

Sample preparation for oxygenated lipids uses the typical strategies in lipidomics, such as organic solvent addition for protein precipitation (PPT). The organic solvent, alone or as a mixture of solvents, can be accompanied by the use of ultrasound (entries 2, 19, 41, 44) [19,63,66,45], microwave or vortex (entry 4) [33] to enhance metabolite extraction. Extraction of SP $(2 \mathrm{OH}), \mathrm{CAR}(3 \mathrm{OH})$ and CAR (DC) is usually done by PPT leading to one single phase systems [4] (Table 1.1).

Lipid extraction is also carried out by applying liquid-liquid extraction (LLE) or solid phase extraction (SPE)-based protocols. The LLE protocol produces the separation of two immiscible layers where metabolites are partitioned according to their polarity, while PPT is carried out simultaneously. Folch or Bligh and Dyer (B\&D) protocols have been extensively used, as is the case for OxCLs and OxCEs (Tables 1.2 and 1.3), and modifications of these have appeared over the years. Both protocols employ mixtures of chloroform and methanol. Some of these modifications include the variation of the water fraction, the use of acidified versions of both methods, and the use of PBS instead of water for the B\&D method (entry 30) [54]. These modifications have appeared to facilitate the separation of the lipid layer from the protein material. Interestingly, other tactics useful for the separation of layers include centrifugation and incubation to $-20^{\circ} \mathrm{C}$ in order to freeze the aqueous fraction, so that it can be easily separated (entry 41) [63]. Additional LLE methods include methyl tert-butyl ether (MTBE) (entries 14, 17, 23) $[25,43,48]$ which benefits from recovering the lipids from the upper, instead of the lower phase, and butanol:methanol (BUME) methods [92]. The BUME method includes two steps (butanol:methanol, followed by heptane:ethyl acetate) and has been fully automatized using a standard 96-tip robot and validated for the extraction of sterols, GPs and SPs [93].

For PPT and LLE, the addition of acids (acetic acid or formic acid) is performed in some cases to enhance extraction of lipids containing carboxylic acid groups, as these lipids will be in the non-charged form (entry 19) [45]. If plasmalogens are the study target, it must be kept in mind that they are very sensitive to an acidic environment, which can cause their degradation [83]. Additionally, while the lipid extraction step aims to break the molecular aggregate to extract the metabolites from the biological matrix using very non-polar solvents such as chloroform, the re-dissolution solvent is selected depending on the solubility of the metabolites of interest and its suitability for the analytical technique. In the case of OxGPs, these are mainly extracted using Folch method but re-dissolved with $\mathrm{MeOH}$ (entry 32) [56].
SPE involves the adsorption of lipids to a solid phase, which both removes the interfering compounds and concentrates the metabolites of interest. SPE protocols have the drawback of being laborious and therefore difficult to apply in large-scale studies. An alternative to overcome this issue is online-SPE, which allows the automatized lipid extraction before analysis in the LC (entry 42) [64]. C8 and C18-based SPE cartridges are amongst the most employed (entry 43) [65] although HILIC-based have been used for OxCLs [94]. Meanwhile, solid phase microextraction (SPME) employs sorbent-coated fibers where lipids migrate and diffuse directly from a headspace or liquid to the fiber, eliminating the washing step necessary for SPE. Then, lipid elution is performed by solvent desorption. The advantages of this method include minimal use of solvents and a small sample volume, which has made it popular for the analysis of oxylipins $[29,30,95]$ and a potential tool in the study of other oxygenated lipids.

To tackle the particularly low concentration of oxygenated lipids, solvent evaporation and consecutive extractions are two approaches often used (entries 13, 23) [40,48]. Thus, while some authors extract with the same solvents (entry 17) [43], other authors do each extraction with a different solvent, or even solvent mixtures, covering distinct polarities. For instance, Calderon et al. compared four different extraction protocols (monophasic vs biphasic systems) to evaluate their performance for lipid extraction from HeLa cells (entry 23) [48]. However, consecutive extractions might have drawbacks such as the introduction of systematic variability, the degradation of metabolites and sample contamination. They are also time consuming, which is a detrimental factor in large-scale studies. This fact can be reflected in the small number of samples per group for most of oxygenated lipid applications $(\mathrm{n}<10)$ (Tables 1.1-1.3). Regarding evaporation of solvent, if it is not carefully performed, it can lead to losing integrity of the chemical structure. Moreover, wherever possible, lipids should be handled under an atmosphere of $\mathrm{N}_{2}$ to flush the air out to prevent oxidative sample damage [83].

\subsection{Specialized oxygenated lipid derivatization approaches}

Although analytical derivatization is a time-consuming step, it is especially beneficial for poorly ionizable or low abundance metabolites. Thus, its advantages often outweigh its inconveniences. In fact, it has proven to be a good solution for lipids detected with low sensitivity and selectivity, insufficient accuracy, matrix effect with serious interferences from similar lipids, presence of isomeric compounds and the lack of isotopic IS. The idea behind derivatization is to attach a chemical reagent (called chemical tagging or chemical labeling), via traditional coupling reactions, photochemical- or microwave-assisted, and, more recently, biocompatible 
click reactions, that specifically react with certain functional groups on the target metabolite [96].

While exciting novel approaches are underway, the lipidomics community derivatizes only in selected instances [96]. Nevertheless, considerable efforts have been tailored and recent literature has extensively reviewed the fundamental reactions commonly used in lipidomics [96], the general types of chemical tags [97] and the most relevant applications focused on the analysis of lipids such as fatty acids [28,98], steroids [79,98], some GPs [28] and oxylipins [30]. All these metabolites present suitable functional groups such as carboxylic acid, hydroxyl, carbonyl or specific locations of double bounds [99] that have served as derivatization sites [97].

Recent research relying on tagging oxygenated lipids still reports classical procedures. A good example is the derivatization of the carboxylic group from highly hydrophilic acyl-L-carnitines based on alkyl ester-type derivatives (e.g. butylation reaction, entry 5 [34], or perfluoroalkylation reaction, entry 11 [38], for adding more hydrophobicity using fluorous tags). It is able to increase their chromatographic retention time (RT) on reversedphase columns [100] and resolve better structural isomers and nominal isobaric species in their detection [101,102] and quantitation [97].

This is also the case of derivatization based on dimethylglycinetype esters to selectively label the hydroxy group at C3 in oxysterols (entry 45 [67]) or the formation of acylhydrazones using 3nitrophenylhydrazine (3NPH) and its labeled version [13C6]3NPH (entry 12) [39] for quantitation of acyl-L-carnitines.

Regarding the derivatization of carbonyl groups, which are present in oxysterols containing the oxo-group, it has been extensively performed based on oxime chemistry to enhance their protonation in electrospray ionization (ESI) [96]. Derivatization to hydrazones has more recently been exploited in LC-MS studies and has been reviewed extensively by Griffiths et al. [79]. Both methods have been used for decades and have been applied recently for OxGPs (entry 24) [90] and acyl-L-carnitines (entry 12) [97].

In general, derivatization strategies have been designed by introducing: (i) alkylating tags to selectively increase hydrophobicity for adjusting RT on column [100]; (ii) stable-charged tags (i.e. charge-tagging), using a fixed charge (i.e. quaternary amine or high proton affinity tertiary amine), to increase solubility in reversedphase solvents and direct fragmentation to provide structural information [97]; and (iii) stable-isotope tags - i.e, isotope-labeling chemical derivatization (ILCD) or stable-isotope labeling derivatization (SILD).

Good proof of this latter type of tags can be seen in a variety of recent examples aimed at derivatization of the acyl chains of acyl-L-carnitines in biological samples, including CAR $(3 \mathrm{OH})$ or CAR (DC). Authors have used deuterium-labeled reagents (e.g. deuterated 1-(3-aminobutyl)-4-(dimethylamino)pyridinium [D0]ABDMAP and [D8]ABDMAP [103]), or 13C-labeled reagents (e.g. [13C2]dansylhydrazine [104] and [13C6]- or [13C12]3NPH [105]).

As for oxysterols, the Griffiths/Wang group has proposed the use of their enzyme-assisted derivatization for sterol analysis (EADSA) methodology using [D0] and [D5] Girard P hydrazine reagents, with charged quaternary nitrogen as part of a pyridine moiety, in an exhaustive study of the metabolites that are incremented in lysosomal storage disorders (entry 43) [65]. Their latest innovation for the in-depth analysis of oxysterols distribution is on-tissue EADSA [106]. In addition, they have reported the use of deuterated 3- $N$-methyl-2-carboxyl rhodamine 6G, [D0] and [D3] MCR6G reagents, to accurately and sensitively quantitate oxysterols in rat blood microdialysates as potential biomarkers for $\mathrm{AD}$ [107].

\section{Liquid chromatography coupled to mass spectrometry (LC- MS) analysis for oxygenated lipids}

During the last decades, high-throughput profiling has had a profound impact in the research of biological and pathological roles of metabolites in living organisms. This strategy has shed light about the broad classes of metabolites in biological organisms. To study the biological role of oxygenated lipids in human diseases, modern MS with high sensitivity, accuracy and resolution, combined with a separation technique such as LC, has shown to have great advantages (Tables 2.1-2.3). Depending on the aim of the analysis, various instrumental settings can be applied for both identification and quantification purposes.

Regarding the chromatography, most of the studies are still based on reversed-phase chromatography (RPLC) using mostly C18 (entries 5, 14, 29, 39, 40) [25,53,62,61,34]. However, other RPLC columns such as C8 (entry 19) [45] and C30 (entry 1) [31] have been used for OxGPs and SP $(2 \mathrm{OH})$, respectively. An interesting example of the use of $\mathrm{C} 8$ is the work by Jia et al., where it allowed the separation of 104 metabolites, including oxysterols, phospholipids, eicosanoids and bile acids (entry 41) [63]. On the contrary, few applications have used normal phase chromatography (NPLC; entries 28, 34, 38) [23,52,60]. In an interesting example, the use of a biphenyl column, which allows the good separation of 8 oxysterols in less than $8 \mathrm{~min}$, also allowed the separation of closely-eluting isomeric pairs such as $7 \alpha$ - and $7 \beta-\mathrm{HC}$ (hydroxycholesterol) (entry 45) [67]. Furthermore, direct infusion (entry 10) [20] and flow-injection analysis (FIA; entries 2, 8) [19,36] have also been applied, avoiding chromatography, although indeed the sample has been processed extensively (i.e. derivatization, several extractions, etc.) before injection. In any case, special attention should be taken for complex mixtures, where the analysis of oxygenated lipids can be very challenging. The interpretation of MS/MS spectra without prior separation can be hard, especially if a large number of isomeric species exist, not to mention the wellknown risk of matrix effect $[9,108,109]$.

Interestingly, in the case of OxCLs, some authors have conducted a classical high-performance thin-layer chromatography (HPTLC)phosphorus analysis to decrease the matrix effect, previous to RPLC-MS analysis (entry 35) [24]. Another attractive strategy to increase selectivity is 2D-LC/MS online analysis, which uses HILIC in the first dimension to eliminate lipid interferences followed by an automatic analyte transfer to perform RPLC separation as the second main dimension [94,110]. The online coupling is faster and prevents sample overhandling, avoiding undesired products.

Regarding the ionization modes, they are mainly ESI (Tables 2.1-2.3). Other ionization sources encompass desorption electrospray ionization (DESI) [111] and atmospheric pressure chemical ionization (APCI) modes. Both are designed to be more efficient and sensitive for low polarity compounds [112,113], i.e. OxCLs (entry 34) [23] and oxysterols (entries 40, 44) [62,66]. Other approaches include liquid extraction surface analysis (LESA) for oxysterols, which enables the direct sampling of metabolites from a solid surface so it can provide helpful information about the distribution of lipids, especially for tissue sections [106,114].

In the case of OxCEs, little has been discussed recently about their analysis by LC-MS [8]. Their ionization in ESI or APCI is relatively poor compared to polar lipids and fatty acids [115]. To overcome this, a popular strategy is to use mobile phase modifiers such as ammonium acetate (entry 38) [60] or ammonium formate (entry 39) [61], which give ammonium adducts of oxCEs and enhance their detection.

In terms of analytical strategies, oxygenated lipids are reported to be analyzed in targeted, semi-targeted, untargeted analysis, or a 
combination of these. Moreover, analytical conditions will depend on the oxygenated lipid properties (ionization polarity, matrix effect, volatility, concentration, isomeric properties).

\subsection{Targeted analysis}

Targeted analysis is the metabolomic approach to detect defined classes of chemically characterized metabolites, often for quantification purposes. As mentioned before, one of the main challenges of oxygenated lipids is their low concentrations, so their analysis needs high sensitivity. Thus, targeted is the most often used method (Tables 2.1-2.3). The triple quadrupole (QqQ) mass spectrometer has been the standard workhorse in this matter, as it offers good sensitivity, reproducibility, and a broad dynamic range.

Targeted analysis usually works in one of two modes: (i) selected reaction monitoring (SRM; i.e. entry 26 [51]) - also known as multiple reaction monitoring (MRM; i.e. entries 2, 14 $[19,25]$ ) - and (ii) parallel reaction monitoring (PRM; i.e. entry 10 [20]) [7]. In the case of MRM, apart from QqQ Q3 has been replaced by a linear ion trap (LIT, resulting in QqLIT) in order to increase sensitivity. This is possible as more ions than a conventional LIT are trapped within a larger space improving mass assignment accuracy and limit of detection [116] (i.e. entry 2 [19]).

While in MRM the selected product ion, after fragmentation, is analyzed by a quadrupole (Q3), for PRM, Q3 is replaced by an Orbitrap. With this strategy, PRM not only has the MRM capability of selectivity by measuring a product ion, but also the qualitative capability because it measures the rest of the fragments. Moreover, the product ions are analyzed with high resolution and accuracy improving selectivity $[9,117]$, which is particularly interesting for analysis of oxygenated lipids.

Other authors state they have performed tandem mass spectrometry (MS/MS or $\mathrm{MS}^{\mathrm{n}}$ ) for targeted analysis using quadrupoletime of flight (QTOF; entry 19) [45], QqLIT (entry 13) [40], or Orbitrap (entry 8) [36].

In the case of acyl-L-carnitines, Yu et al. described a comprehensive identification based on two-step MS data acquisitions, where the first LC-full scan MS/data dependent analysis (DDA) and $\mathrm{MS} / \mathrm{MS}$ monitoring (MS/DDA-MS ${ }^{2}$ ) is used to detect all acyl-Lcarnitine precursors based on characteristic fragments, followed by multi-run LC-full scan MS combined with PRM acquisition (entry 7) [35]. In the last step, a database with 758 acyl-L-carnitines together with exact mass, RT and MS/MS information was developed and applied to study biological samples. The authors were able to annotate 241, 515 and 222 acyl-L-carnitines in human plasma, urine and rat liver tissue, respectively [35]. Other mass spectrometers such as ion mobility MS have also started to be applied to the study of oxygenated lipids in targeted analysis, as it is the case for oxysterols [118]. In addition, commercial kits such as Biocrates ${ }^{\circledR}$ have been used for SP $(2 \mathrm{OH})$, CAR $(3 \mathrm{OH})$ and CAR (DC) (entries 2, 3, 8) [19,36,32].

In general, targeted analysis, either from an in-house method or applying commercial kits, will not allow the discovery of new oxygenated species. Consequently, the objective of the studies in targeted analysis has been the profiling of the different oxygenated classes of lipids (entries 2, 13) [19,40], method development for validation of their findings (entries 5, 14, 28) [25,52,34] or discovering the role of specific oxygenated species (entries 15, 19) [41,45].

In these strategies, the use of standards is compulsory, as they are needed for characterization (mass and RT), structural identification (fragmentation pattern), transitions (parent ion/product ion, capillary and fragmentation voltages) and quantification. For oxygenated lipids, the efforts that have been made to develop useful standards warrant further discussion.

\subsubsection{Quantitative considerations: oxygenated standards}

In a perfect scenario, each targeted oxygenated lipid would be referred to a standard via a calibration curve that covers the expected concentration range (external calibration) or added to the sample (internal calibration). However, the feasibility of this approach is limited by the availability of oxygenated standards. In the case of oxysterols, more than 30 standards, including isotopelabeled, are commercially available [9], and thus are widely used (entries 39-45) [65,62-64,66,67,61]. In contrast, standards for the other classes of oxygenated lipids are fewer and often prohibitively expensive, owing to their greater synthetic difficulty. So far, only 12 OxGPs are commercially available. From these, 8 oxidized glycerophosphatidylcholines (OxPCs) species containing a fragmented, oxidized short-chain fatty acid remnant at the sn-2 position, are available: (i) C4 truncated (16:0-succinoyl PC and POBPC), (ii) C5 truncated (KOdiAPC, POVPC and PGPC), and (iii) C9 truncated (KDdiAPC, PONPC and PAzPC, entries 14-16) [14-16]. In addition, 2 long-chain OxPCs and 2 oxidized glycero phosphoethanolamine (OxPEs) standards from arachidonic acid (AA) -2 hydroperoxides (HPETEs) and 2 hydroxides (HETEs) - are available. As for OxCEs, there are 6 derivatives of cholesteryl linoleate (LA-CE) with a hydroxide modification (Ch-HODEs) available. It is especially remarkable that there are 4 deuterated standards currently available for OxGPs: [6D]PGPC, [9D]PAzPC1 and [14D] and [9D]POVPC.

To address this dearth of standards several approaches rely on in-house prepared mixtures of oxidized species generated in vitro, from non-oxidized commercial ones, (entries 17, 18, 26, 27) $[17,18,26,27]$, as has been reviewed recently [119]. Thus, PAPC, SAPC, PLPC, and SAPE among others, and commercial TMCL, TLCL or bovine heart CL (BHCL) (with different content in TLCL depending on the provider), have been widely used to carry out different oxidation procedures, Table 2.2 [27,56,43,94,120]. Good examples are photo-oxidation (UVA irradiation) (entries 26) [51,55], airexposure oxidation (entry 18) [44], or under free radical conditions through already established methods such as the Fenton reaction ( $\mathrm{Fe}(\mathrm{II}) / \mathrm{H}_{2} \mathrm{O}_{2}$ ) for GPs (entries 17, 27) [27]. In the case of OxCEs, in a recent example, the LA-CE and cholesteryl arachidonate (AA$\mathrm{CE}$ ) oxidation products were formed in an azo-initiated peroxidation (free radical-induced oxidation) and yielded CE hydroperoxides (CEOOHs: including Ch-HpODE and Ch-HpETE), which can be reduced to CE hydroxides (CEOHs: Ch-HODE and Ch-HETE) by TPP (entry 38) [60].

A recent multi-laboratory study at four different locations evaluated the OxPAPC products generated by air oxidation by LC-MS/MS, focusing on the identification and relative quantitation of lipid peroxidation products [90]. Although the overall oxidation pattern and the most abundant OxGPs remained consistent, there was a notable difference in the degree of oxidation. Consequently, the authors not only strongly recommend the MS evaluation of the in-house prepared mixtures, but also introduce the use of a "truncated score". This calculation could shed light on the contribution of short- and long-chain lipid peroxidation products [90].

Additionally, commercial innovations such as mixes of OxPAPC are available. Oxidation of PAPC generates a well-characterized mixture of OxGPs containing either fragmented - POVPC and PGPC - or full-length oxygenated sn-2 residues and also complex cyclization or rearrangement products (PEIPC). In addition, a mixture of the primary oxidized unsaturated fatty acid components 
of atherosclerotic plaques is also available, and it includes ChHODE, as well as the free, non-esterified oxylipins.

Finally, standards can also be included in commercial kits - such as the aforementioned Biocrates ${ }^{\circledR}$ - (entries 2,3,8) [19,36,32].

\subsection{Semi-targeted analysis}

The lack of commercial standards has limited the application of targeted methods and has led to the application of semi-targeted methods. These include precursor ion scan (PIS; entry 26) and neutral loss scan (NLS). These scan techniques utilize specific fragments or neutral losses generated in the tandem MS to identify metabolites from the same class of lipids. In the case of oxylipins analysis by PIS, the fragment ion $m / z 115$ is known to be the diagnostic ion for the presence of hydroxy or epoxy functional groups in arachidonic acyl chain modified in C5 [9,121]. Through a PIS semitargeted approach using a QqLIT spectrometer, Narzt et al. (entry 26) [51] tried to uncover the influence of the OxPAPC generated in primary human epidermal keratinocytes UVA irradiation, identifying a plethora of bioactive OxPC species together with five novel molecular species. Another semi-targeted example was carried out by Kelkar et al. (entry 27) [27], thanks to which the authors recognized the serine hydrolase lipase ABHD12 as the principal oxidized glycerophosphatidylserine (OxPS) regulator in the mammalian brain under severe inflammatory stress.

\subsection{Non-targeted analysis}

Unlike targeted analysis, non-targeted analysis provides the comprehensive analysis of all the measurable analytes in a sample, including chemical unknowns. Therefore, it is more suitable for de novo identification of oxygenated lipids. For this approach, a highresolution MS (HRMS) platform is necessary to determine the exact mass and thereby discriminate each lipid species. QTOF (entry 22) [26], ion trap-TOF (IT-TOF; entry 4) [33], Orbitrap (entry 34) [23], and Fourier transform ion cyclotron resonance (FT-ICR; entry 21) [47] mass spectrometers have been mainly used.

Regarding the analytical applications, non-targeted analysis has been used for discovery of new oxygenated species (entry 22) [26] or lipid profiling characterization (entry 4) [33]. Additionally, it has been performed with the aim of searching specific metabolites or for their structural characterization (including fragmentation pattern) to later move into targeted analysis (entries 4, 22, 31, 39) $[26,61,33,55]$. Other purposes for moving from non-targeted to targeted analysis include the validation of findings using a different analytical technique (entries 12, 21) [39,47].

Important aspects in HRMS are the acquisition methods. These are mainly DDA and data-independent acquisition (DIA) [122-125]. There are two types of DIA strategies, (i) all-ion fragmentation (AIF, also known as $\mathrm{MS}^{\mathrm{ALL}}$ and $\mathrm{MS}^{\mathrm{E}}$ ) and (ii) sequential window acquisition of all theoretical fragment ion spectra (SWATH) [125]. These acquisition methods can be crucial in the analysis of oxygenated lipids as they can increase the annotation coverage, especially when a specific software for identification is used. As examples of these, DDA acquisition has been applied in the study of OxCLs (entry 36) [58] while SWATH has been used as a new approach to increase annotation in lipidomics including OxGPs (entry 23 [48]).

Another interesting approach that has been applied in oxygenated lipidomics is mass spectrometry imaging (MSI), a technique that shows the spatial distribution of lipids within cells and tissues. This provides an essential component to complete the entire biological picture in a lipidomic study. Yin et al. described the specific localization of four OxPC in pancreatic islets by nDESI-MSI suggesting them as potential biomarkers for monitoring the production of ROS, which could be harmful to pancreatic beta cells (entry 20) [46]. Other recent on-tissue applications include, in the case of oxysterols, the use of on-tissue EADSA with microscale-liquid extraction for surface analysis ( $\mu$ LESA)-LC-MS by the Griffiths/Wang group to study in detail cholesterol metabolism in the brain [106].

\subsection{Structure annotation of oxidized lipids}

The annotation of oxygenated lipids is a complex task, mainly due to the number of isomers available for each exact mass. Special care must be taken in presenting the results, as authors may report a compound from an isomeric pair without considering possible coelutions. In the case of oxysterols, a relevant example of frequent misrepresentation is the isomery between $7 \alpha$ - and $7 \beta-\mathrm{HC}$. Examples of good reporting can be found in entries 42 and 45 [64,67]. In entry 42 , authors report they were not able to separate the pair and thus refer to them jointly as $7 \alpha / 7 \beta-\mathrm{HC}$ [64], while in entry 45 authors are capable of separating these isomers and correctly report them as $7 \alpha$ - and $7 \beta-\mathrm{HC}$ [67].

In any case, within the last years, undeniable progress has been made in the identification of oxidized lipids (classes II and III). So far, the greatest attention has been paid to OxGPs, which somehow reflects their widespread involvement in many processes. To support their annotation in untargeted analyses, dedicated software, databases/libraries and pipelines have been developed.

Although the number of tools designed for lipidomics is large, programs dedicated to oxidized lipids are very few. The leader in the field of the identification of oxidized lipids and the automation of this process is the research group led by Fedorova. They developed LPPTiger software for automated annotation of OxGPs [126]. In-silico oxidation of five main GP classes leads to create the list of possible oxidation products. Known fragmentation patterns are used to create the list of expected fragments and neutral losses, which are subsequently searched against negative ion mode DDA datasets. Another software, LipidMatch, uses in-silico fragmentation libraries to search either DDA or DIA datasets, acquired in both ion modes, and although it was not designed exclusively for oxidized lipids, OxGPs contribute to 56 lipid types covered in this software [127]. In LPPTiger the user can generate oxidation products of any intact phospholipid, which results in an unlimited number of OxGPs, while in LipidMatch the list of OxGPs is predefined and is therefore restricted. Both pieces of software cover long- and short-chain oxidized lipids, while LPPTiger includes also cyclic oxidized lipids. CEU Mass Mediator, a web-based service for metabolites annotation, also offers solutions aiding the annotation of short- and log-chain OxPCs [128]. Firstly, the composition of fatty acids is determined based on accurate mass matching and then proposed structures of the entire lipid are given, including in silico predicted candidates. Because the input value is the $m / z$ of fatty acids and precursors, this approach is suitable for DDA and DIA. In terms of multiple candidates, clues about expected fragments or neutral losses are provided, to inspect either positive or negative ion mode spectra to confirm or disclaim given candidates.

We also have to mention Lipostar software, which is a very complex solution for targeted and untargeted LC-MS based lipidomics, covering not only lipid identification but also data acquisition and advanced multivariate analysis [129]. For annotation, two complementary approaches are implemented: one approach searches for matches of fragmented lipids across databases, while the other is database-independent and is based on the 
interpretation of the experimental MS/MS spectra searching for lipid-class-specific fragments. A unique feature of this software is testing every unidentified ion for possible oxidation.

Kendrick mass defect (KMD) was already successfully implemented in various tools for lipid annotation. However, so far it was rather used based on the hydrogen $\operatorname{KMD}(\mathrm{H})$ to visualize the degree of unsaturation, but nowadays, visualization based on the oxygen $\operatorname{KMD}(\mathrm{O})$ allows to track the oxidation product. Such strategy was used for annotation of OxCLs and monolyso-CLs [94]. Multiple 3D$\mathrm{KMD}$ are built by plotting horizontally $\mathrm{KMD}(\mathrm{H})$ against vertical $\operatorname{KMD}(\mathrm{O})$, and $\mathrm{RT}$ as third dimension represented through colorcoded heat map. This plot was implemented in MZmine 2 where together with database matching provides robust tool for annotation of OxCLs [92].

An entirely different approach was implemented in LOBSTAHS tool, which in contrast to previous softwares, uses MS1 information for the annotation [130]. Orthogonal criteria, based on ionization and adducts formation patterns together with RT filtration, are used for tentative annotation of lipids. Similarly to LipidMatch, LOBSTAHS was not designed solely for oxidized lipids, but among 14,000 unique entries of oxidized species are included, covering not only OxGPs, but also glycerolipids, polyunsaturated aldehydes and fatty acids. HRMS data from positive and negative ion modes are used to make the assignments from one of two fully customizable databases. Supporting Fig. S1 shows the graphical summary of mentioned software and different sources of information used for the annotation of oxidized lipids.

In most cases, annotation starts with the accurate mass matching against either open-access databases or in-house built libraries. To the present day, there are no databases exclusively dedicated to the products of lipid oxidation. Within lipid-oriented databases lipid mediators are easily accessible, while the early products of oxidations are either completely missing or represented by very few records. However, this situation is changing in LipidMaps, the most sophisticated lipid-focused database. Over the last two years, an almost ten-fold increase in the number of OxGPs was observed (May 25, 2018: 26 entries; November 25, 2020: 259 entries).

Pipelines give an important insight into lipid annotation, established based on good practices and experience. There are two publications describing such pipelines, both focused on OxGPs [26,131]. Ryohei Aoyagi et al. established a workflow consisting of two main steps: first stage is to conduct untargeted MS/MS to build spectral library through analysis of biogenic OxGPs. In the second step, acquired fragmentation spectra are used to develop broadtargeted MRM method for quantification of previously identified OxGPs [131]. Lopez-Lopez and colleagues established a pipeline for annotation of OxGPs combining information from MS1 and MS/MS level, giving attention to unannotated spectra and searching for the oxidation signs. Also, spectral comparison of the fragmentation pattern of intact and oxidized lipids was incorporated in the annotation process [26].

In summary, there is a clear need to extend our current knowledge about early oxidation products for the other groups of lipids included in this review. Oxygenated lipids are poorly explored; therefore, tools aiding fully untargeted annotation are in high interest.

\section{Oxygenated lipids as potential biomarkers}

Identification of potential biomarkers will certainly contribute to the diagnosis, staging, prognosis and medical treatment in many diseases if these cross the line from research to the clinic [132]. Metabolites can be good biomarkers as they can be explained in the context of a metabolic pathway; however, to date, this is not case for oxygenated lipids, where their signaling role is not fully understood.

A potential biomarker goes beyond a statistically significant metabolite in a comparison and we have reviewed their characteristics elsewhere [132]. One of them is that they must undergo validation. There are different levels of validation: the analytical validation implies the use of a second analytical technique to corroborate the identity and the results [47], while the biological validation requires a broader cohort.

To our knowledge, there is still no validated biomarker in the group of oxygenated lipids we cover in this review. We present here the first findings of potential biomarkers (Supporting Tables S1.1S1.4).

Regarding SP (2OH), they have been studied in metabolic syndrome [31], AD [19], neurological outcome in cardiac arrest [32] and cholangiocarcinoma [33]. As for acyl-L-carnitines, considerable effort has been taken to develop new methods for their comprehensive profiling including CAR (3OH) and CAR (DC) species $[20,21,35,38,34,39,36,37]$. Various CAR $(30 H)$ and CAR (DC) have been found to be implicated in inborn errors of metabolism [20], diabetes mellitus and metabolic syndrome [21,38,34] among others (Supporting Table S1.1).

Regarding OxGPs, the onset and progression of multiple pathologies have been linked with the alterations of their levels. Recently, novel insights have been revealed related to coronary artery disease (CAD) [45,40], cardiopulmonary disorders [41], oxidative stress [44], severe inflammatory stress [27], and different cancer types [23,26,54], among many others (Supporting Table S1.2a). It is worthy of highlighting the work performed by Najdekr et al. (entry 21) [47] to uncover potential biomarkers for medium-chain acyl-CoA dehydrogenase deficiency (MCADD) by analyzing dry blood spots. The three OxGPs found as discriminatory molecules between MCADD patients and controls were validated in a second larger and well-designed cohort. As for OxCLs, their levels were found significantly altered in hepatocellular carcinoma [54] and oncologic thyroid tissue [23] (Supporting Table S1.2b).

In the case of OxCEs, efforts have been made, especially in cardiovascular diseases (CVD), where their role is probably important as part of OxLDL $[17,75,61]$. A recent study suggested that levels of OxCE might serve as a potential biomarker for different types of CVD, especially myocardial infarction (MI) [60]. All in all, the scarceness of data for these compounds warrants further investigation that perfects their detection methods and delves into their role in pathologies (Supporting Table S1.2c).

Finally, in the case of oxysterols, their potential as biomarkers has been studied in many pathologies and is reviewed in depth elsewhere [18]. The most remarkable metabolites in this regard are 7-ketocholesterol (7-KC) and cholestan-3 $\beta, 5 \alpha, 6 \beta$-triol (C-triol), which have been widely used for the diagnosis of genetic disorders such as NPC and CTX (Fig. 1C [65,67]). However, they are not ideal biomarkers since they lack specificity and can be produced by ex vivo cholesterol oxidation, generating misleading results $[133,134]$. 7-KC in particular is highly important in CVD and aging due to its cytotoxicity [133]. Apart from CVD [62], we highlight studies of oxysterols in liver injury [63], neurological disorders [64] and inflammatory bowel disease (IBD) [66] (Supporting Table S1.3).

\section{Conclusions}

To sum up, there is not a single protocol suitable to extract the entire set of oxygenated lipids from biological samples. Furthermore, some oxygenated lipids from classes II and III, if found after a non-targeted methodology where conditions were not controlled, could be spurious. 
Targeted LC-MS methods have still some significant limitations, which have hindered the development in the study of oxygenated lipids, including the limited availability of standards. Meanwhile, untargeted analysis is limited by the low sensitivity towards oxygenated lipids due to generic sample pretreatments and the problems to obtain an unequivocal identification. It is also important to mention that highly reputed journals should pay more attention to methodological questions, since sometimes the lack of detailed protocols makes the reproducibility of the assays difficult.

This topic has gained interest and great concern of researchers, who agree that standardized protocols are needed. However, these are already difficult to address for lipidomics, and therefore even more so when speaking of oxygenated lipids. Great efforts have been made in this review to unify procedures from very different areas (clinical, organic, analytical, computational, etc.), including naming conventions, to try to reach a consensus with unified language, and to structure and order such a complex field. In this regard, the Lipidomics Standards Initiative (LSI) aims to standardize the reporting of lipidomics data and analyses, and the terminology used [135]. The result from these efforts should help researchers in their experimental design and help the advance of such an interesting area of lipidomics research.

\section{Author contributions (CRediT)}

Alma Villaseñor: Investigation, Data Curation, Writing - Original Draft, Writing - Review \& Editing, Visualization. Joanna Godzien: Investigation, Data Curation, Writing - Review \& Editing, Visualization. Tomás Clive Barker-Tejeda: Investigation, Data Curation, Writing - Review \& Editing, Visualization. Carolina Gonzalez-Riano: Investigation, Data Curation, Writing - Review \& Editing, Visualization. Ángeles López-López: Investigation, Data Curation, Writing - Review \& Editing, Visualization. Danuta Dudzik: Investigation, Data Curation, Writing - Review \& Editing, Visualization. Ana Gradillas: Conceptualization, Data Curation, Writing - Review \& Editing, Visualization, Supervision. Coral Barbas: Conceptualization, Writing - Review \& Editing, Supervision, Project administration, Funding acquisition.

\section{Declaration of competing interest}

The authors declare that they have no known competing financial interests or personal relationships that could have appeared to influence the work reported in this paper.

\section{Acknowledgements}

This work was supported by Ministry of Science, Innovation and Universities of Spain (Ref. RTI2018-095166-B-I00) and "la Caixa" Foundation (Ref. 01-09-2018-01-09-2020). T.C.B-T and A.L.L. thank CEU-International Doctoral School (CEINDO) for their fellowship. Funding sources were not involved in the writing of the manuscript.

\section{Appendix A. Supplementary data}

Supplementary data to this article can be found online at https://doi.org/10.1016/j.trac.2021.116367.

\section{References}

[1] T.A. Lydic, Y.H. Goo, Lipidomics unveils the complexity of the lipidome in metabolic diseases, Clin. Transl. Med. 7 (2018) 4. https://doi.org/10.1186/ s40169-018-0182-9.

[2] Q. Yu, Z. He, D. Zubkov, S. Huang, I. Kurochkin, X. Yang, T. Halene, L. Willmitzer, P. Giavalisco, S. Akbarian, P. Khaitovich, Lipidome alterations in human prefrontal cortex during development, aging, and cognitive disorders, Mol. Psychiatr. (2018). https://doi.org/10.1038/s41380-018-0200-8.

[3] X. Han, Lipidomics for health and disease, in: Lipidomics, John Wiley \& Sons, Ltd, 2016, pp. 377-404. https://doi.org/10.1002/9781119085263.ch17.

[4] J. Aldana, A. Romero-Otero, M.P. Cala, Exploring the lipidome: current lipid extraction techniques for mass spectrometry analysis, Metabolites 10 (2020). https://doi.org/10.3390/metabo10060231.

[5] T. Züllig, M. Trötzmüller, H.C. Köfeler, Lipidomics from sample preparation to data analysis: a primer, Anal. Bioanal. Chem. 412 (2020) 2191-2209. https:// doi.org/10.1007/s00216-019-02241-y.

[6] K. Jurowski, K. Kochan, J. Walczak, M. Barańska, W. Piekoszewski, B. Buszewski, Analytical techniques in lipidomics: state of the art, Crit. Rev. Anal. Chem. 47 (2017) 418-437. https://doi.org/10.1080/10408347.2017. 1310613.

[7] C.M. Spickett, A.R. Pitt, Oxidative lipidomics coming of age: advances in analysis of oxidized phospholipids in physiology and pathology, Antioxidants Redox Signal. 22 (2015) 1646-1666. https://doi.org/10.1089/ ars.2014.6098.

[8] L. Li, S. Zhong, X. Shen, Q. Li, W. Xu, Y. Tao, H. Yin, Recent development on liquid chromatography-mass spectrometry analysis of oxidized lipids, Free Radic. Biol. Med. 144 (2019) 16-34. https://doi.org/10.1016/j.freeradbiomed. 2019.06.006.

[9] Z. Ni, L. Goracci, G. Cruciani, M. Fedorova, Computational solutions in redox lipidomics - current strategies and future perspectives, Free Radic. Biol. Med. 144 (2019) 110-123. https://doi.org/10.1016/j.freeradbiomed.2019.04.027.

[10] Y.Y. Tyurina, V.A. Tyurin, T. Anthonymuthu, A.A. Amoscato, L.J. Sparvero, A.M. Nesterova, M.L. Baynard, W. Sun, R. He, P. Khaitovich, Y.A. Vladimirov, D.I. Gabrilovich, H. Bayır, V.E. Kagan, Redox lipidomics technology: looking for a needle in a haystack, Chem. Phys. Lipids 221 (2019) 93-107. https:// doi.org/10.1016/j.chemphyslip.2019.03.012.

[11] H. Hama, Fatty acid 2-Hydroxylation in mammalian sphingolipid biology, Biochim. Biophys. Acta 1801 (2010) 405-414. https://doi.org/10.1016/ j.bbalip.2009.12.004.

[12] Y. Miura, The biological significance of $\omega$-oxidation of fatty acids, Proc. Jpn Acad. Ser. B Phys. Biol. Sci. 89 (2013) 370-382. https://doi.org/10.2183/ pjab.89.370.

[13] J.K. Reddy, T. Hashimoto, Peroxisomal beta-oxidation and peroxisome proliferator-activated receptor alpha: an adaptive metabolic system, Annu. Rev. Nutr. 21 (2001) 193-230. https://doi.org/10.1146/annurev.nutr.21. 1.193.

[14] H. Yin, L. Xu, N.A. Porter, Free radical lipid peroxidation: mechanisms and analysis, Chem. Rev. 111 (2011) 5944-5972. https://doi.org/10.1021/ cr200084z.

[15] A. Reis, C.M. Spickett, Chemistry of phospholipid oxidation, Biochim. Biophys. Acta 1818 (2012) 2374-2387. https://doi.org/10.1016/j.bbamem.2012. 02.002.

[16] V.N. Bochkov, O.V. Oskolkova, K.G. Birukov, A.-L. Levonen, C.J. Binder, J. Stöckl, Generation and biological activities of oxidized phospholipids, Antioxidants Redox Signal. 12 (2010) 1009-1059.

[17] S. Zhong, L. Li, X. Shen, Q. Li, W. Xu, X. Wang, Y. Tao, H. Yin, An update on lipid oxidation and inflammation in cardiovascular diseases, Free Radic. Biol. Med. 144 (2019) 266-278. https://doi.org/10.1016/j.freeradbiomed. 2019.03.036.

[18] B. Sottero, D. Rossin, E. Staurenghi, P. Gamba, G. Poli, G. Testa, Omics analysis of oxysterols to better understand their pathophysiological role, Free Radic. Biol. Med. 144 (2019) 55-71. https://doi.org/10.1016/j.freeradbiomed.2019. 05.026.

[19] V.R. Varma, A.M. Oommen, S. Varma, R. Casanova, Y. An, R.M. Andrews, R. O'Brien, O. Pletnikova, J.C. Troncoso, J. Toledo, R. Baillie, M. Arnold, G. Kastenmueller, K. Nho, P.M. Doraiswamy, A.J. Saykin, R. Kaddurah-Daouk, C. Legido-Quigley, M. Thambisetty, Brain and blood metabolite signatures of pathology and progression in Alzheimer disease: a targeted metabolomics study, PLoS Med. 15 (2018), e1002482. https://doi.org/10.1371/ journal.pmed.1002482.

[20] C.A. Pickens, K. Petritis, High resolution mass spectrometry newborn screening applications for quantitative analysis of amino acids and acylcarnitines from dried blood spots, Anal. Chim. Acta 1120 (2020) 85-96. https:// doi.org/10.1016/j.aca.2020.04.067.

[21] L. Xiang, J. Wei, X.Y. Tian, B. Wang, W. Chan, S. Li, Z. Tang, H. Zhang W.S. Cheang, Q. Zhao, H. Zhao, Z. Yang, Y. Hong, Y. Huang, Z. Cai, Comprehensive analysis of acylcarnitine species in $\mathrm{db} / \mathrm{db}$ mouse using a novel method of high-resolution parallel reaction monitoring reveals widespread metabolic dysfunction induced by diabetes, Anal. Chem. 89 (2017) 10368-10375. https://doi.org/10.1021/acs.analchem.7b02283.

[22] M.G. Schooneman, F.M. Vaz, S.M. Houten, M.R. Soeters, Acylcarnitines: reflecting or inflicting insulin resistance? Diabetes 62 (2013) 1-8. https:// doi.org/10.2337/db12-0466.

[23] J. Zhang, W. Yu, S.W. Ryu, J. Lin, G. Buentello, R. Tibshirani, J. Suliburk, L.S. Eberlin, Cardiolipins are biomarkers of mitochondria-rich thyroid oncocytic tumors, Canc. Res. 76 (2016) 6588-6597. https://doi.org/10.1158/ 0008-5472.can-16-1545.

[24] Y.Y. Tyurina, A.M. Polimova, E. Maciel, V.A. Tyurin, V.I. Kapralova, D.E. Winnica, A.S. Vikulina, M.R. Domingues, J. McCoy, L.H. Sanders, H. Bayır, J.T. Greenamyre, V.E. Kagan, LC/MS analysis of cardiolipins in substantia nigra and plasma of rotenone-treated rats: implication for mitochondrial 
dysfunction in Parkinson's disease, Free Radic. Res. 49 (2015) 681-691. https://doi.org/10.3109/10715762.2015.1005085.

[25] O.S. Ademowo, H.K.I. Dias, I. Milic, A. Devitt, R. Moran, R. Mulcahy, A.N. Howard, J.M. Nolan, H.R. Griffiths, Phospholipid oxidation and carotenoid supplementation in Alzheimer's disease patients, Free Radic. Biol. Med. 108 (2017) 77-85. https://doi.org/10.1016/j.freeradbiomed.2017.03.008.

[26] Á. López-López, J. Godzien, B. Soldevilla, A. Gradillas, Á. López-Gonzálvez, A. Lens-Pardo, A. La Salvia, M. del Carmen Riesco-Martínez, R. García-Carbonero, C. Barbas, Oxidized lipids in the metabolic profiling of neuroendocrine tumors-analytical challenges and biological implications, J. Chromatogr. A (2020) 461233.

[27] D.S. Kelkar, G. Ravikumar, N. Mehendale, S. Singh, A. Joshi, A.K. Sharma, A. Mhetre, A. Rajendran, H. Chakrapani, S.S. Kamat, A chemical-genetic screen identifies ABHD12 as an oxidized-phosphatidylserine lipase, Nat. Chem. Biol. 15 (2019) 169-178.

[28] F. Wei, S. Lamichhane, M. Orešič, T. Hyötyläinen, Lipidomes in health and disease: analytical strategies and considerations, TrAC Trends Anal. Chem. (Reference Ed.) 120 (2019) 115664. https://doi.org/10.1016/j.trac.2019. 115664.

[29] I. Liakh, A. Pakiet, T. Sledzinski, A. Mika, Modern methods of sample preparation for the analysis of oxylipins in biological samples, Molecules 24 (2019). https://doi.org/10.3390/molecules24081639.

[30] I. Liakh, A. Pakiet, T. Sledzinski, A. Mika, Methods of the analysis of oxylipins in biological samples, Molecules 25 (2020). https://doi.org/10.3390/ molecules25020349.

[31] L. Veillon, S. Go, W. Matsuyama, A. Suzuki, M. Nagasaki, Y. Yatomi, J. Inokuchi, Identification of ganglioside GM3 molecular species in human serum associated with risk factors of metabolic syndrome, PloS One 10 (2015), e0129645. https://doi.org/10.1371/journal.pone.0129645.

[32] A. Boerlin, T. Luescher, C. Becker, S. Perrig, E. Thommen, M. Widmer, K. Beck, A. Vincent, K. Tisljar, L. Bernasconi, P. Neyer, P. Schuetz, R. Sutter, S. Marsch, S. Hunziker, Low plasma sphingomyelin levels show a weak association with poor neurological outcome in cardiac arrest patients: results from the prospective, observational COMMUNICATE trial, J. Clin. Med. 9 (2020) 17. https://doi.org/10.3390/jcm9040897.

[33] A. Silsirivanit, C. Phoomak, K. Teeravirote, S. Wattanavises, W. Seubwai, C. Saengboonmee, Z. Zhan, J.I. Inokuchi, A. Suzuki, S. Wongkham, Overexpression of HexCer and LacCer containing 2-hydroxylated fatty acids in cholangiocarcinoma and the association of the increase of LacCer (d18:1h23:0) with shorter survival of the patients, Glycoconj. J. 36 (2019) 103-111. https://doi.org/10.1007/s10719-019-09864-4.

[34] P. Giesbertz, J. Ecker, A. Haag, B. Spanier, H. Daniel, An LC-MS/MS method to quantify acylcarnitine species including isomeric and odd-numbered forms in plasma and tissues, J. Lipid Res. 56 (2015) 2029-2039. https://doi.org/ 10.1194/jlr.D061721.

[35] D. Yu, L. Zhou, Q. Xuan, L. Wang, X. Zhao, X. Lu, G. Xu, Strategy for comprehensive identification of acylcarnitines based on liquid chromatography-high-resolution mass spectrometry, Anal. Chem. 90 (2018) 5712-5718. https://doi.org/10.1021/acs.analchem.7b05471.

[36] J.W. Thompson, K.J. Adams, J. Adamski, Y. Asad, D. Borts, J.A. Bowden, G. Byram, V. Dang, W.B. Dunn, F. Fernandez, O. Fiehn, D.A. Gaul, A.F. Hühmer, A. Kalli, T. Koal, S. Koeniger, R. Mandal, F. Meier, F.J. Naser, D. O'Neil, A. Pal, G.J. Patti, H. Pham-Tuan, C. Prehn, F.I. Raynaud, T. Shen, A.D. Southam, L. St John-Williams, K. Sulek, C.G. Vasilopoulou, M. Viant, C.L. Winder, D. Wishart, L. Zhang, J. Zheng, M.A. Moseley, International ring trial of a high resolution targeted metabolomics and lipidomics platform for serum and plasma analysis, Anal. Chem. 91 (2019) 14407-14416. https://doi.org/ 10.1021/acs.analchem.9b02908.

[37] X. Yan, S.P. Markey, R. Marupaka, Q. Dong, B.T. Cooper, Y.A. Mirokhin, W.E. Wallace, S.E. Stein, Mass spectral library of acylcarnitines derived from human urine, Anal. Chem. 92 (2020) 6521-6528. https://doi.org/10.1021/ acs.analchem.0c00129.

[38] P.E. Minkler, M.S.K. Stoll, S.T. Ingalls, J. Kerner, C.L. Hoppel, Validated method for the quantification of free and total carnitine, butyrobetaine, and acylcarnitines in biological samples, Anal. Chem. 87 (2015) 8994-9001. https:// doi.org/10.1021/acs.analchem.5b02198.

[39] D. Meierhofer, Acylcarnitine profiling by low-resolution LC-MS, PloS One 14 (2019), e0221342. https://doi.org/10.1371/journal.pone.0221342.

[40] J.Y. Lee, S.K. Byeon, M.H. Moon, Profiling of oxidized phospholipids in lipoproteins from patients with coronary artery disease by hollow fiber flow field-flow fractionation and nanoflow liquid chromatography-tandem mass spectrometry, Anal. Chem. 87 (2015) 1266-1273.

[41] Y. Ke, P. Karki, J. Kim, S. Son, E. Berdyshev, V.N. Bochkov, A.A. Birukova, K.G. Birukov, Elevated truncated oxidized phospholipids as a factor exacerbating ALI in the aging lungs, Faseb. J. 33 (2019) 3887-3900. https://doi.org/ 10.1096/fj.201800981R

[42] M. Philippova, O.V. Oskolkova, W. Bicker, A.W. Schoenenberger, T.J. Resink, P. Erne, V.N. Bochkov, Analysis of fragmented oxidized phosphatidylcholines in human plasma using mass spectrometry: comparison with immune assays, Free Radic. Biol. Med. 144 (2019) 167-175.

[43] O.S. Ademowo, P. Sharma, P. Cockwell, A. Reis, I.L. Chapple, H.R. Griffiths, I.H.K. Dias, Distribution of plasma oxidised phosphatidylcholines in chronic kidney disease and periodontitis as a co-morbidity, Free Radic. Biol. Med. 146 (2020) 130-138. https://doi.org/10.1016/j.freeradbiomed.2019.10.012.
[44] V. Serbulea, C.M. Upchurch, M.S. Schappe, P. Voigt, D.E. DeWeese, B.N. Desai, A.K. Meher, N. Leitinger, Macrophage phenotype and bioenergetics are controlled by oxidized phospholipids identified in lean and obese adipose tissue, Proc. Natl. Acad. Sci. Unit. States Am. 115 (2018) E6254-E6263.

[45] M. Chatterjee, D. Rath, J. Schlotterbeck, J. Rheinlaender, B. Walker-Allgaier, N. Alnaggar, M. Zdanyte, I. Müller, O. Borst, T. Geisler, Regulation of oxidized platelet lipidome: implications for coronary artery disease, Eur. Heart J. 38 (2017) 1993-2005.

[46] R. Yin, J. Kyle, K. Burnum-Johnson, K.J. Bloodsworth, L. Sussel, C. Ansong, J. Laskin, High spatial resolution imaging of mouse pancreatic islets using nanospray desorption electrospray ionization mass spectrometry, Anal. Chem. 90 (2018) 6548-6555.

[47] L. Najdekr, A. Gardlo, L. Mádrová, D. Friedecký, H. Janečková, E.S. Correa, R. Goodacre, T. Adam, Oxidized phosphatidylcholines suggest oxidative stress in patients with medium-chain acyl-CoA dehydrogenase deficiency, Talanta 139 (2015) 62-66.

[48] C. Calderón, C. Sanwald, J. Schlotterbeck, B. Drotleff, M. Lämmerhofer, Comparison of simple monophasic versus classical biphasic extraction protocols for comprehensive UHPLC-MS/MS lipidomic analysis of Hela cells, Anal. Chim. Acta 1048 (2019) 66-74.

[49] A.-C. Almstrand, D. Voelker, R.C. Murphy, Identification of oxidized phospholipids in bronchoalveolar lavage exposed to low ozone levels using multivariate analysis, Anal. Biochem. 474 (2015) 50-58.

[50] J.S. Yang, J.Y. Kim, J.C. Lee, M.H. Moon, Investigation of lipidomic perturbations in oxidatively stressed subcellular organelles and exosomes by asymmetrical flow field-flow fractionation and nanoflow ultrahigh performance liquid chromatography-tandem mass spectrometry, Anal. Chim. Acta 1073 (2019) 79-89.

[51] M.-S. Narzt, I.-M. Nagelreiter, O. Oskolkova, V.N. Bochkov, J. Latreille, M. Fedorova, Z. Ni, F.J. Sialana, G. Lubec, M. Filzwieser, A novel role for NUPR1 in the keratinocyte stress response to UV oxidized phospholipids, Redox Biol 20 (2019) 467-482.

[52] J.C. Martens, G. Keilhoff, W. Halangk, T. Wartmann, A. Gardemann, I. Päge, L. Schild, Lipidomic analysis of molecular cardiolipin species in livers exposed to ischemia/reperfusion, Mol. Cell. Biochem. 400 (2015) 253-263. https://doi.org/10.1007/s11010-014-2282-1.

[53] C. Wolke, S. Gürtler, D. Peter, J. Weingärtner, G. Domanska, U. Lendeckel, L. Schild, Vitamin B6 deficiency in new born rats affects hepatic cardiolipin composition and oxidative phosphorylation, Exp Biol Med Maywood 244 (2019) 1619-1628. https://doi.org/10.1177/1535370219889880.

[54] H. Zhong, M. Xiao, K. Zarkovic, M. Zhu, R. Sa, J. Lu, Y. Tao, Q. Chen, L. Xia, S. Cheng, G. Waeg, N. Zarkovic, H. Yin, Mitochondrial control of apoptosis through modulation of cardiolipin oxidation in hepatocellular carcinoma: a novel link between oxidative stress and cancer, Free Radic. Biol. Med. 102 (2017) 67-76. https://doi.org/10.1016/j.freeradbiomed.2016.10.494.

[55] G. Mao, F. Qu, C.M. St Croix, Y.Y. Tyurina, J. Planas-Iglesias, J. Jiang, Z. Huang, A.A. Amoscato, V.A. Tyurin, A.A. Kapralov, A. Cheikhi, J. Maguire, J. KleinSeetharaman, H. Bayır, V.E. Kagan, Mitochondrial redox opto-lipidomics reveals mono-oxygenated cardiolipins as pro-apoptotic death signals, ACS Chem. Biol. 11 (2016) 530-540. https://doi.org/10.1021/acschembio.5b0 0737.

[56] G.Y. Liu, S.H. Moon, C.M. Jenkins, M. Li, H.F. Sims, S. Guan, R.W. Gross, The phospholipase $\operatorname{iPLA}(2) \gamma$ is a major mediator releasing oxidized aliphatic chains from cardiolipin, integrating mitochondrial bioenergetics and signaling, J. Biol. Chem. 292 (2017) 10672-10684. https://doi.org/10.1074/ jbc.M117.783068.

[57] J.R. Buland, K.J. Wasserloos, V.A. Tyurin, Y.Y. Tyurina, A.A. Amoscato, R.K. Mallampalli, B.B. Chen, J. Zhao, Y. Zhao, S. Ofori-Acquah, V.E. Kagan, B.R. Pitt, Biosynthesis of oxidized lipid mediators via lipoprotein-associated phospholipase A2 hydrolysis of extracellular cardiolipin induces endothelial toxicity, Am. J. Physiol. Lung Cell Mol. Physiol. 311 (2016) L303-L316. https://doi.org/10.1152/ajplung.00038.2016.

[58] H. Chao, T.S. Anthonymuthu, E.M. Kenny, A.A. Amoscato, L.K. Cole, G.M. Hatch, J. Ji, V.E. Kagan, H. Bayır, Disentangling oxidation/hydrolysis reactions of brain mitochondrial cardiolipins in pathogenesis of traumatic injury, JCI Insight 3 (2018). https://doi.org/10.1172/jci.insight.97677.

[59] J. Ji, S. Baart, A.S. Vikulina, R.S. Clark, T.S. Anthonymuthu, V.A. Tyurin, L. Du, C.M. St Croix, Y.Y. Tyurina, J. Lewis, E.M. Skoda, A.E. Kline, P.M. Kochanek, P. Wipf, V.E. Kagan, H. Bayır, Deciphering of mitochondrial cardiolipin oxidative signaling in cerebral ischemia-reperfusion, J. Cerebr. Blood Flow Metabol. 35 (2015) 319-328. https://doi.org/10.1038/jcbfm.2014.204.

[60] S. Guo, J. Lu, Y. Zhuo, M. Xiao, X. Xue, S. Zhong, X. Shen, C. Yin, L. Li, Q. Chen, M. Zhu, B. Chen, M. Zhao, L. Zheng, Y. Tao, H. Yin, Endogenous cholesterol ester hydroperoxides modulate cholesterol levels and inhibit cholesterol uptake in hepatocytes and macrophages, Redox Biol 21 (2019) 101069. https://doi.org/10.1016/j.redox.2018.101069.

[61] A.A. Rasmiena, C.K. Barlow, T.W. Ng, D. Tull, P.J. Meikle, High density lipoprotein efficiently accepts surface but not internal oxidised lipids from oxidised low density lipoprotein, Biochim. Biophys. Acta 1861 (2016) 69-77. https://doi.org/10.1016/j.bbalip.2015.11.002.

[62] U. Ceglarek, J. Dittrich, J. Leopold, C. Helmschrodt, S. Becker, H. Staab, O. Richter, S. Rohm, G. Aust, Free cholesterol, cholesterol precursor and plant sterol levels in atherosclerotic plaques are independently associated with 
symptomatic advanced carotid artery stenosis, Atherosclerosis 295 (2020) 18-24. https://doi.org/10.1016/j.atherosclerosis.2019.12.018.

[63] M. Jia, Z. Peng, K. Yang, C. Su, Y. Wang, C. Yan, A high-throughput targeted metabolomics method for the quantification of 104 non-polar metabolites in cholesterol, eicosanoid, and phospholipid metabolism: application in the study of a CCl, Analyst 145 (2020) 3575-3591. https://doi.org/10.1039/ d0an00385a.

[64] M. Reinicke, J. Schröter, D. Müller-Klieser, C. Helmschrodt, U. Ceglarek, Free oxysterols and bile acids including conjugates - simultaneous quantification in human plasma and cerebrospinal fluid by liquid chromatography-tandem mass spectrometry, Anal. Chim. Acta 1037 (2018) 245-255. https://doi.org/ 10.1016/j.aca.2018.02.049.

[65] W.J. Griffiths, E. Yutuc, J. Abdel-Khalik, P.J. Crick, T. Hearn, A. Dickson, B.W. Bigger, T. Hoi-Yee Wu, A. Goenka, A. Ghosh, S.A. Jones, D.F. Covey, D.S. Ory, Y. Wang, Metabolism of non-enzymatically derived oxysterols: clues from sterol metabolic disorders, Free Radic. Biol. Med. 144 (2019) 124-133. https://doi.org/10.1016/j.freeradbiomed.2019.04.020.

[66] O. Guillemot-Legris, V. Mutemberezi, B. Buisseret, A. Paquot, V. Palmieri, P. Bottemanne, J. Lemaire, J.-F. ois Rahier, M. Alhouayek, G.G. Muccioli, Colitis alters oxysterol metabolism and is affected by $4 \beta$-hydroxycholesterol administration, J. Crohns Colitis. 13 (2019) 11. https://doi.org/10.1093/eccojcc/jjy157.

[67] Z. Pataj, G. Liebisch, G. Schmitz, S. Matysik, Quantification of oxysterols in human plasma and red blood cells by liquid chromatography high-resolution tandem mass spectrometry, J. Chromatogr. A 1439 (2016) 82-88. https:// doi.org/10.1016/j.chroma.2015.11.015.

[68] G. Liebisch, E. Fahy, J. Aoki, E.A. Dennis, T. Durand, C.S. Ejsing, M. Fedorova, I. Feussner, W.J. Griffiths, H. Köfeler, A.H. Merrill, R.C. Murphy, V.B. O'Donnell, O. Oskolkova, S. Subramaniam, M.J.O. Wakelam, F. Spener, Update on LIPID MAPS classification, nomenclature, and shorthand notation for MS-derived lipid structures, J. Lipid Res. 61 (2020) 1539-1555. https://doi.org/10.1194/ jlr.S120001025.

[69] Y.A. Hannun, L.M. Obeid, Sphingolipids and their metabolism in physiology and disease, Nat. Rev. Mol. Cell Biol. 19 (2018) 175-191. https://doi.org/ 10.1038/nrm.2017.107.

[70] N. Longo, M. Frigeni, M. Pasquali, Carnitine transport and fatty acid oxidation, Biochim. Biophys. Acta 1863 (2016) 2422-2435. https://doi.org/ 10.1016/j.bbamcr.2016.01.023.

[71] J.T. Marquês, H.S. Marinho, R.F.M. de Almeida, Sphingolipid hydroxylation in mammals, yeast and plants - an integrated view, Prog. Lipid Res. 71 (2018) 18-42. https://doi.org/10.1016/j.plipres.2018.05.001.

[72] A.S. Koh, F. Gao, J. Liu, K.T. Fridianto, J. Ching, R.S. Tan, J.-I. Wong, S.J. Chua, S. Leng, L. Zhong, B.M. Keng, F.Q. Huang, J.-M. Yuan, W.-P. Koh, J.-P. Kovalik, Metabolomic profile of arterial stiffness in aged adults, Diabetes Vasc. Dis. Res. 15 (2018) 74-80. https://doi.org/10.1177/1479164117733627.

[73] B. Školová, A. Kováčik, O. Tesař, L. Opálka, K. Vávrová, Phytosphingosine, sphingosine and dihydrosphingosine ceramides in model skin lipid membranes: permeability and biophysics, Biochim. Biophys. Acta BBA - Biomembr. 1859 (2017) 824-834. https://doi.org/10.1016/j.bbamem.2017. 01.019 .

[74] I. Levitan, S. Volkov, P.V. Subbaiah, Oxidized LDL: diversity, patterns of recognition, and pathophysiology, Antioxidants Redox Signal. 13 (2010) 39-75. https://doi.org/10.1089/ars.2009.2733.

[75] S.H. Choi, D. Sviridov, Y.I. Miller, Oxidized cholesteryl esters and inflammation, Biochim. Biophys. Acta Mol. Cell Biol. Lipids 1862 (2017) 393-397. https://doi.org/10.1016/j.bbalip.2016.06.020.

[76] F. Collin, Chemical basis of reactive oxygen species reactivity and involvement in neurodegenerative diseases, Int. J. Mol. Sci. 20 (2019). https:// doi.org/10.3390/ijms20102407.

[77] V.E. Kagan, Y.Y. Tyurina, V.A. Tyurin, D. Mohammadyani, J.P.F. Angeli, S.V. Baranov, J. Klein-Seetharaman, R.M. Friedlander, R.K. Mallampalli, M. Conrad, Cardiolipin signaling mechanisms: collapse of asymmetry and oxidation, Antioxidants Redox Signal. 22 (2015) 1667-1680.

[78] S.S. Davies, L. Guo, Lipid peroxidation generates biologically active phospholipids including oxidatively $\mathrm{N}$-modified phospholipids, Chem. Phys. Lipids 181 (2014) 1-33. https://doi.org/10.1016/j.chemphyslip.2014.03.002.

[79] W.J. Griffiths, J. Abdel-Khalik, P.J. Crick, E. Yutuc, Y. Wang, New methods for analysis of oxysterols and related compounds by LC-MS, J. Steroid Biochem. Mol. Biol. 162 (2016) 4-26. https://doi.org/10.1016/j.jsbmb.2015.11.017.

[80] V. Mutemberezi, O. Guillemot-Legris, G.G. Muccioli, Oxysterols: from cholesterol metabolites to key mediators, Prog. Lipid Res. 64 (2016) 152-169. https://doi.org/10.1016/j.plipres.2016.09.002.

[81] C. Zerbinati, L. Iuliano, Cholesterol and related sterols autoxidation, Free Radic. Biol. Med. 111 (2017) 151-155. https://doi.org/10.1016/j.freeradbiomed.2017.04.013.

[82] Z.A.M. Zielinski, D.A. Pratt, H-atom abstraction vs addition: accounting for the diverse product distribution in the autoxidation of cholesterol and its esters, J. Am. Chem. Soc. 141 (2019) 3037-3051. https://doi.org/10.1021/ jacs.8b11524.

[83] X. Han, Lipidomics: Comprehensive Mass Spectrometry of Lipids, Wiley, Wiley.Com. (n.d.), https://www.wiley.com/en-us/Lipidomics\%3A+Comprehensive + Mass + Spectrometry + of + Lipids-p-9781118893128. (Accessed 29 October 2020).

[84] C.Z. Ulmer, J.P. Koelmel, C.M. Jones, T.J. Garrett, J.J. Aristizabal-Henao, H.W. Vesper, J.A. Bowden, A review of efforts to improve lipid stability during sample preparation and standardization efforts to ensure accuracy in the reporting of lipid measurements, Lipids 56 (2021) 3-16. https://doi.org/ 10.1002/lipd.12263.

[85] C. Gonzalez-Riano, S. Tapia-González, A. García, A. Muñoz, J. DeFelipe, C. Barbas, Metabolomics and neuroanatomical evaluation of post-mortem changes in the hippocampus, Brain Struct. Funct. 222 (2017) 2831-2853. https://doi.org/10.1007/s00429-017-1375-5.

[86] C. Gonzalez-Riano, G. León-Espinosa, M. Regalado-Reyes, A. García, J. DeFelipe, C. Barbas, Metabolomic study of hibernating Syrian hamster brains: in search of neuroprotective agents, J. Proteome Res. 18 (2019) 1175-1190. https://doi.org/10.1021/acs.jproteome.8b00816.

[87] X. Wang, X. Gu, H. Song, Q. Song, X. Gao, Y. Lu, H. Chen, Phenylmethanesulfonyl fluoride pretreatment stabilizes plasma lipidome in lipidomic and metabolomic analysis, Anal. Chim. Acta 893 (2015) 77-83. https://doi.org/10.1016/j.aca.2015.08.049.

[88] H.S. Jonasdottir, H. Brouwers, R.E. Toes, A. Ioan-Facsinay, M. Giera, Effects of anticoagulants and storage conditions on clinical oxylipid levels in human plasma, Biochim. Biophys. Acta BBA-Mol. Cell Biol. Lipids. 1863 (2018) $1511-1522$.

[89] J. Dorow, S. Becker, L. Kortz, J. Thiery, S. Hauschildt, U. Ceglarek, Preanalytical investigation of polyunsaturated fatty acids and eicosanoids in human plasma by liquid chromatography-tandem mass spectrometry, Biopreserv. Biobanking 14 (2016) 107-113.

[90] Z. Ni, B.C. Sousa, S. Colombo, C.B. Afonso, T. Melo, A.R. Pitt, C.M. Spickett, P. Domingues, M.R. Domingues, M. Fedorova, Evaluation of air oxidized PAPC: a multi laboratory study by LC-MS/MS, Free Radic. Biol. Med. 144 (2019) 156-166.

[91] K.G. Lee, G.B. Lee, J.S. Yang, M.H. Moon, Perturbations of lipids and oxidized phospholipids in lipoproteins of patients with postmenopausal osteoporosis evaluated by asymmetrical flow field-flow fractionation and nanoflow UHPLC-ESI-MS/MS, Antioxidants 9 (2020) 46.

[92] B. Reichl, N. Eichelberg, M. Freytag, J. Gojo, A. Peyrl, W. Buchberger, Evaluation and optimization of common lipid extraction methods in cerebrospinal fluid samples, J. Chromatogr. B 1153 (2020) 122271. https://doi.org/10.1016/ j.jchromb.2020.122271.

[93] L. Löfgren, M. Ståhlman, G.-B. Forsberg, S. Saarinen, R. Nilsson, G.I. Hansson, The BUME method: a novel automated chloroform-free 96-well total lipid extraction method for blood plasma, J. Lipid Res. 53 (2012) 1690-1700. https://doi.org/10.1194/jlr.D023036.

[94] P.O, K.A, H.H. Helmer, Analysis of artificially oxidized cardiolipins and monolyso-cardiolipins via liquid chromatography/high-resolution mass spectrometry and Kendrick mass defect plots after hydrophilic interaction liquid chromatography based sample preparation, Rapid Commun. Mass Spectrom. 34 (2020), e8566. https://doi.org/10.1002/rcm.8566.

[95] A. Napylov, N. Reyes-Garces, G. Gomez-Rios, M. Olkowicz, S. Lendor, C. Monnin, B. Bojko, C. Hamani, J. Pawliszyn, D. Vuckovic, In vivo solid-phase microextraction for sampling of oxylipins in brain of awake, moving rats, Angew Chem. Int. Ed. Engl. 59 (2020) 2392-2398. https://doi.org/10.1002/ anie.201909430.

[96] Y. Wang, W.J. Griffiths, in: CHAPTER 6:Derivatisation for Direct Infusionand Liquid Chromatography-Mass Spectrometry, Lipidomics, 2020, pp. 122-147. https://doi.org/10.1039/9781788013109-00122.

[97] T. Huang, M.R. Armbruster, J.B. Coulton, J.L. Edwards, Chemical tagging in mass spectrometry for systems biology, Anal. Chem. 91 (2019) 109-125. https://doi.org/10.1021/acs.analchem.8b04951.

[98] X.E. Zhao, S. Zhu, H. Liu, Recent progresses of derivatization approaches in the targeted lipidomics analysis by mass spectrometry, J. Separ. Sci. 43 (2020) 1838-1846. https://doi.org/10.1002/jssc.201901346.

[99] P. Esch, S. Heiles, Investigating C[double bond, length as m-dash]C positions and hydroxylation sites in lipids using Paterno-Buchi functionalization mass spectrometry, Analyst 145 (2020) 2256-2266. https://doi.org/10.1039/ c9an02260k.

[100] J. Ni, L. Xu, W. Li, L. Wu, Simultaneous determination of thirteen kinds of amino acid and eight kinds of acylcarnitine in human serum by LC-MS/MS and its application to measure the serum concentration of lung cancer patients: simultaneous determination of thirteen kinds of amino acid and eight kinds of acylcarnitine in human serum by LC-MS/MS and its application to measure, Biomed. Chromatogr. 30 (2016) 1796-1806. https://doi.org/10.1002/bmc.3755.

[101] F.R. Mansour, W. Wei, N.D. Danielson, Separation of carnitine and acylcarnitines in biological samples: a review: review of separation methods for carnitine compounds, Biomed. Chromatogr. 27 (2013) 1339-1353. https:// doi.org/10.1002/bmc.2995.

[102] S. Li, D. Gao, Y. Jiang, Function, detection and alteration of acylcarnitine metabolism in hepatocellular carcinoma, Metabolites 9 (2019) 36. https:// doi.org/10.3390/metabo9020036.

[103] S. Li, D. Gao, C. Song, C. Tan, Y. Jiang, Isotope labeling strategies for acylcarnitines profile in biological samples by liquid chromatography-mass spectrometry, Anal. Chem. 91 (2019) 1701-1705. https://doi.org/10.1021/ acs.analchem.8b05120.

[104] G. Chen, Q. Zhang, Simultaneous quantification of free fatty acids and acylcarnitines in plasma samples using dansylhydrazine labeling and liquid chromatography-triple quadrupole mass spectrometry, Anal. Bioanal. Chem. 412 (2020) 2841-2849. https://doi.org/10.1007/s00216-020-02514-x.

[105] J. Han, R. Higgins, M.D. Lim, K. Atkinson, J. Yang, K. Lin, C.H. Borchers, Isotope-labeling derivatization with 3-nitrophenylhydrazine for LC/ 
multiple-reaction monitoring-mass-spectrometry-based quantitation of carnitines in dried blood spots, Anal. Chim. Acta 1037 (2018) 177-187. https://doi.org/10.1016/j.aca.2018.01.045.

[106] E. Yutuc, R. Angelini, M. Baumert, N. Mast, I. Pikuleva, J. Newton, M.R. Clench, D.O.F. Skibinski, O.W. Howell, Y. Wang, W.J. Griffiths, Localization of sterols and oxysterols in mouse brain reveals distinct spatial cholesterol metabolism, Proc Natl Acad Sci U A 117 (2020) 5749-5760. https://doi.org/ 10.1073/pnas.1917421117.

[107] X. Wang, J. Sun, X.E. Zhao, Y. Xu, L. Sun, S. Zhu, J. You, X. Wang, Stable isotope labeling derivatization coupled with magnetic dispersive solid phase extraction for the determination of hydroxyl-containing cholesterol and metabolites by in vivo microdialysis and ultra-high performance liquid chromatography tandem mass spectrometry, J. Chromatogr. A 1594 (2019) 23-33. https://doi.org/10.1016/j.chroma.2019.02.021.

[108] J. Draper, A.J. Lloyd, R. Goodacre, M. Beckmann, Flow infusion electrospray ionisation mass spectrometry for high throughput, non-targeted metabolite fingerprinting: a review, Metabolomics 9 (2013) 4-29. https://doi.org/ 10.1007/s11306-012-0449-x.

[109] R. González-Domínguez, A. Sayago, Á. Fernández-Recamales, Direct infusion mass spectrometry for metabolomic phenotyping of diseases, Bioanalysis 9 (2017) 131-148. https://doi.org/10.4155/bio-2016-0202.

[110] P.O. Helmer, C.M. Wienken, A. Korf, H. Hayen, Mass spectrometric investigation of cardiolipins and their oxidation products after two-dimensional heart-cut liquid chromatography, J. Chromatogr. A 1619 (2020) 460918. https://doi.org/10.1016/j.chroma.2020.460918.

[111] C.S. Clendinen, M.E. Monge, F.M. Fernández, Ambient mass spectrometry in metabolomics, Analyst 142 (2017) 3101-3117. https://doi.org/10.1039/ c7an00700k.

[112] C.N. Pitman, W.R. LaCourse, Desorption atmospheric pressure chemical ionization: a review, Anal. Chim. Acta 1130 (2020) 146-154. https://doi.org/ 10.1016/j.aca.2020.05.073.

[113] R. Wang, L. Zhang, Z. Zhang, Y. Tian, Comparison of ESI- and APCI-LC-MS/MS methods: a case study of levonorgestrel in human plasma, J Pharm Anal 6 (2016) 356-362. https://doi.org/10.1016/j.jpha.2016.03.006.

[114] A.N. Conner, J.R. Jarvis, L.J. Alderwick, R.L. Griffiths, Direct liquid extraction surface analysis mass spectrometry of cell wall lipids from mycobacteria: salt additives for decreased spectral complexity, Rapid Commun. Mass Spectrom. (2019). https://doi.org/10.1002/rcm.8523.

[115] J.A. Bowden, C.J. Albert, O.S. Barnaby, D.A. Ford, Analysis of cholesteryl esters and diacylglycerols using lithiated adducts and electrospray ionizationtandem mass spectrometry, Anal. Biochem. 417 (2011) 202-210. https:// doi.org/10.1016/j.ab.2011.06.015.

[116] H.V. Botitsi, S.D. Garbis, A. Economou, D.F. Tsipi, Current mass spectrometry strategies for the analysis of pesticides and their metabolites in food and water matrices, Mass Spectrom. Rev. 30 (2011) 907-939. https://doi.org/ 10.1002/mas.20307.

[117] D. Yu, T.W.T. Rupasinghe, B.A. Boughton, S.H.A. Natera, C.B. Hill, P. Tarazona, I. Feussner, U. Roessner, A high-resolution HPLC-QqTOF platform using parallel reaction monitoring for in-depth lipid discovery and rapid profiling, Anal. Chim. Acta 1026 (2018) 87-100. https://doi.org/10.1016/j.aca.2018. 03.062 .

[118] P. Kylli, T. Hankemeier, R. Kostiainen, Feasibility of ultra-performance liquid chromatography-ion mobility-time-of-flight mass spectrometry in analyzing oxysterols, J. Chromatogr. A 1487 (2017) 147-152. https://doi.org/10.1016/ j.chroma.2017.01.039.

[119] T.C. Barker-Tejeda, A. Villaseñor, C. Gonzalez-Riano, Á. López-López, A. Gradillas, C. Barbas, In vitro generation of oxidized standards for lipidomics. Application to major membrane lipid components, J. Chromatogr. A 1651 (2021) 462254. https://doi.org/10.1016/j.chroma.2021.462254.
[120] Z. Chen, Y. Wu, Y.S. Ma, Y. Kobayashi, Y.Y. Zhao, Y. Miura, H. Chiba, S.P. Hui, Profiling of cardiolipins and their hydroperoxides in HepG2 cells by LC/MS, Anal. Bioanal. Chem. 409 (2017) 5735-5745. https://doi.org/10.1007/ s00216-017-0515-3.

[121] T. Petta, L.A.B. Moraes, L.H. Faccioli, Versatility of tandem mass spectrometry for focused analysis of oxylipids, J. Mass Spectrom. JMS. 50 (2015) 879-890. https://doi.org/10.1002/jms.3595.

[122] P. Barbier Saint Hilaire, K. Rousseau, A. Seyer, S. Dechaumet, A. Damont, C. Junot, F. Fenaille, Comparative evaluation of data dependent and data independent acquisition workflows implemented on an Orbitrap fusion for untargeted metabolomics, Metabolites 10 (2020). https://doi.org/10.3390/ metabo10040158.

[123] A. Doerr, DIA mass spectrometry, Nat. Methods 12 (2015). https://doi.org/ 10.1038/nmeth.3234, 35-35.

[124] H. Tsugawa, A. Satoh, H. Uchino, T. Cajka, M. Arita, M. Arita, Mass spectrometry data repository enhances novel metabolite discoveries with advances in computational metabolomics, Metabolites 9 (2019). https:// doi.org/10.3390/metabo9060119.

[125] B. Drotleff, J. Illison, J. Schlotterbeck, R. Lukowski, M. Lämmerhofer, Comprehensive lipidomics of mouse plasma using class-specific surrogate calibrants and SWATH acquisition for large-scale lipid quantification in untargeted analysis, Anal. Chim. Acta 1086 (2019) 90-102. https://doi.org/ 10.1016/j.aca.2019.08.030.

[126] Z. Ni, G. Angelidou, R. Hoffmann, M. Fedorova, LPPtiger software for lipidome-specific prediction and identification of oxidized phospholipids from LC-MS datasets, Sci. Rep. 7 (2017) 15138. https://doi.org/10.1038/ s41598-017-15363-Z.

[127] J.P. Koelmel, N.M. Kroeger, C.Z. Ulmer, J.A. Bowden, R.E. Patterson, J.A. Cochran, C.W.W. Beecher, T.J. Garrett, R.A. Yost, LipidMatch: an automated workflow for rule-based lipid identification using untargeted highresolution tandem mass spectrometry data, BMC Bioinf. 18 (2017) 331. https://doi.org/10.1186/s12859-017-1744-3.

[128] A. Gil de la Fuente, F. Traldi, J. Siroka, A. Kretowski, M. Ciborowski, A. Otero, C. Barbas, J. Godzien, Characterization and annotation of oxidized glycerophosphocholines for non-targeted metabolomics with LC-QTOF-MS data, Anal. Chim. Acta 1037 (2018) 358-368. https://doi.org/10.1016/ j.aca.2018.08.005.

[129] L. Goracci, S. Tortorella, P. Tiberi, R.M. Pellegrino, A. Di Veroli, A. Valeri, G. Cruciani, Lipostar, a comprehensive platform-neutral cheminformatics tool for lipidomics, Anal. Chem. 89 (2017) 6257-6264. https://doi.org/ 10.1021/acs.analchem.7b01259.

[130] J.R. Collins, B.R. Edwards, H.F. Fredricks, B.A. Van Mooy, LOBSTAHS: an adduct-based lipidomics strategy for discovery and identification of oxidative stress biomarkers, Anal. Chem. 88 (2016) 7154-7162. https://doi.org/ 10.1021/acs.analchem.6b01260.

[131] R. Aoyagi, K. Ikeda, Y. Isobe, M. Arita, Comprehensive analyses of oxidized phospholipids using a measured MS/MS spectra library, J. Lipid Res. 58 (2017) 2229-2237. https://doi.org/10.1194/jlr.D077123.

[132] Á. López-López, Á. López-Gonzálvez, T.C. Barker-Tejeda, C. Barbas, A review of validated biomarkers obtained through metabolomics, Expert Rev. Mol. Diagn. 18 (2018) 557-575. https://doi.org/10.1080/14737159.2018.1481391.

[133] A. Anderson, A. Campo, E. Fulton, A. Corwin, W.G. Jerome, M.S. O'Connor, 7Ketocholesterol in disease and aging, Redox Biol 29 (2020) 101380. https:// doi.org/10.1016/j.redox.2019.101380.

[134] W.J. Griffiths, Y. Wang, Sterolomics in biology, biochemistry, medicine, Trends Anal. Chem. 120 (2019) 115280. https://doi.org/10.1016/j.trac.2018. 10.016 .

[135] Guidelines - lipidomics-standards-initiative (LSI) (n.d.), https://lipidomicsstandards-initiative.org/guidelines. (Accessed 30 October 2020). 